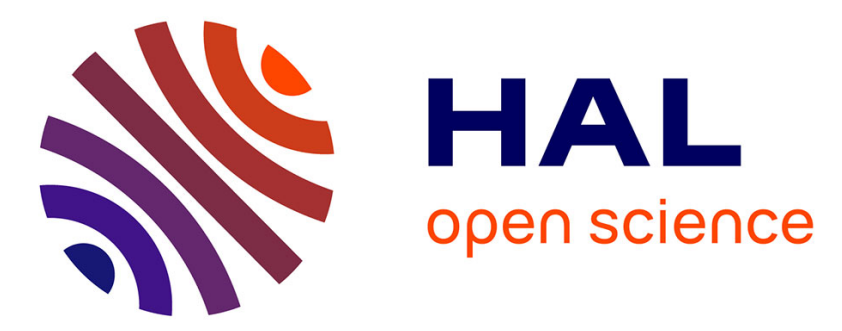

\title{
Aerosol climatology: dependence of the Angstrom exponent on wavelength over four AERONET sites
}

D. G. Kaskaoutis, H. D. Kambezidis, N. Hatzianastassiou, P. G.

Kosmopoulos, K. V. S. Badarinath

\section{- To cite this version:}

D. G. Kaskaoutis, H. D. Kambezidis, N. Hatzianastassiou, P. G. Kosmopoulos, K. V. S. Badarinath. Aerosol climatology: dependence of the Angstrom exponent on wavelength over four AERONET sites. Atmospheric Chemistry and Physics Discussions, 2007, 7 (3), pp.7347-7397. hal-00302819

\section{HAL Id: hal-00302819 https://hal.science/hal-00302819}

Submitted on 30 May 2007

HAL is a multi-disciplinary open access archive for the deposit and dissemination of scientific research documents, whether they are published or not. The documents may come from teaching and research institutions in France or abroad, or from public or private research centers.
L'archive ouverte pluridisciplinaire HAL, est destinée au dépôt et à la diffusion de documents scientifiques de niveau recherche, publiés ou non, émanant des établissements d'enseignement et de recherche français ou étrangers, des laboratoires publics ou privés. 
Aerosol optical properties

\section{Aerosol climatology: dependence of the Angstrom exponent on wavelength over four AERONET sites}

D. G. Kaskaoutis ${ }^{1,2}$, H. D. Kambezidis ${ }^{2}$, N. Hatzianastassiou ${ }^{2}$, P. G. Kosmopoulos ${ }^{3}$, and K. V. S. Badarinath ${ }^{4}$

${ }^{1}$ Atmospheric Research Team, Institute for Environmental Research and Sustainable Development, National Observatory of Athens, Lofos Nymphon, P.O. Box 20048, 11810, Athens, Greece

${ }^{2}$ University of loannina, Department of Physics, Laboratory of Meteorology, 45110 Ioannina, Greece

${ }^{3}$ University of Athens, Department of Geology, University campus 15784, Athens Greece

${ }^{4}$ Atmospheric Science Section, National Remote Sensing Agency (Dept. of Space-Govt. of India) Balanagar, Hyderabad-500 037, India

Received: 17 April 2007 - Accepted: 11 May 2007 - Published: 30 May 2007

Correspondence to: D. G. Kaskaoutis (dkask@meteo.noa.gr)
D. G. Kaskaoutis et al.

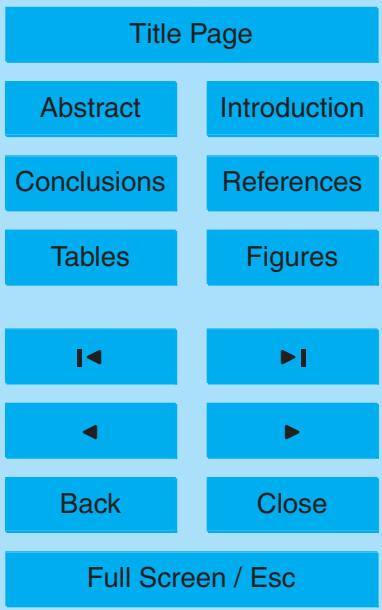

Printer-friendly Version

Interactive Discussion 


\section{Abstract}

The Ångström exponent, $\alpha$, is often used as a qualitative indicator of aerosol particle size. In this study, aerosol optical depth (AOD) and Ångström exponent $(\alpha)$ data were analyzed to obtain information about the adequacy of the simple use of the Ångström 5 exponent for characterizing aerosols, and for exploring possibilities for a more efficient characterization of aerosols. This was made possible by taking advantage of the spectral variation of $\alpha$, the so-called curvature. The data were taken from four selected AERONET stations, which are representative of four aerosol types, i.e. biomass burning, pollution, desert dust and maritime. Using the least-squares method, the Angström- $\alpha$ was calculated in the spectral interval $340-870 \mathrm{~nm}$, along with the coefficients $\alpha_{1}$ and $\alpha_{2}$ of the second order polynomial fit to the plotted logarithm of AOD versus the logarithm of wavelength, and the second derivative of $\alpha$. The results show that the spectral curvature can provide important additional information about the different aerosol types, and can be effectively used to discriminate between them, since the 15 fine-mode particles exhibit negative curvature, while the coarse-mode aerosols positive. In addition, the curvature has always to be taken into account in the computations of Ångström exponent values in the spectral intervals $380-440 \mathrm{~nm}$ and $675-870 \mathrm{~nm}$, since fine-mode aerosols exhibit larger $\alpha_{675-870}$ than $\alpha_{380-440}$ values, and vice-versa for coarse-mode particles. A second-order polynomial fit simulates the spectral dependence of the AODs very well, while the associated constant term varies proportionally to the aerosol type. The correlation between the coefficients $\alpha_{1}$ and $\alpha_{2}$ of the secondorder polynomial fit and the Ångström exponent $\alpha$, and the atmospheric turbidity, is further investigated. The obtained results reveal important features, which can be used for better discriminating between different aerosol types.
Aerosol optical properties

D. G. Kaskaoutis et al.

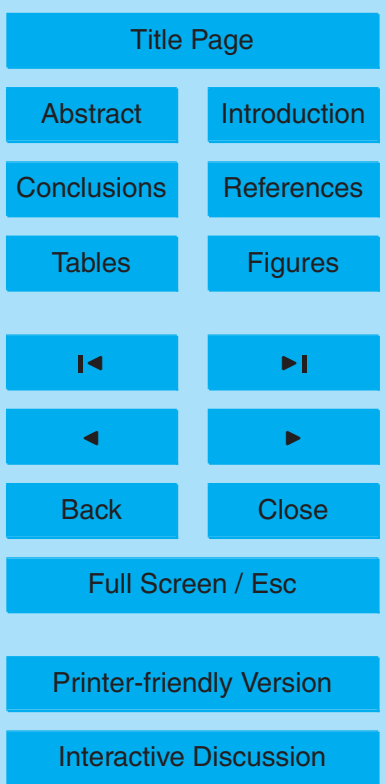




\section{Introduction}

Atmospheric aerosols are among the major climatic forcing agents. Their radiative forcing, on a global average, is likely to be comparable in magnitude to the radiative forcing of about $2.4 \mathrm{~W} \mathrm{~m}^{-2}$ by anthropogenic greenhouse gases (IPCC, 2001). Nevertheless, 5 their effect is difficult to estimate, mainly because there is incomplete knowledge of their optical properties (Houghton et al., 1996; Hansen et al., 2000), resulting thus in a large uncertainty regarding the aerosol overall radiative forcing (Granger Morgan et al., 2006; Remer and Kaufman, 2006; Yu et al., 2006). This is due to the fact that, opposite to well-mixed atmospheric gases, aerosols are highly inhomogeneous variable in space and time. Therefore, there is a need for global and continuous monitoring of aerosol properties (physico-chemical and optical). The climatic effect of aerosols depends strongly on their optical properties. The importance of these properties, namely the aerosol optical depth (AOD), the Ångström parameter, and the aerosol size distribution functions, is also high for atmospheric and remote sensing studies, ments and analyses of aerosol optical properties at as many locations on earth as possible (Ogunjobi et al., 2004). These measurements have to be taken at as many wavelengths as possible, given the strong spectral dependence of both aerosol properties and radiation. Measurements of aerosol optical properties involve in-situ, and satellite remote sensing data. These data sets are complemented with those of field campaigns (ground-based and airborne), for calibration and validation of satellite data.

The satellite remote sensing technique provides nonintrusive measurements and global coverage. However, radiation measured from satellites depends on the earth's surface reflectance, and extraction of the aerosol contribution presently has a limited 25 accuracy (Kaufman et al., 1997; King et al., 1999). Although many problems related to satellite observations of aerosols have been resolved by sophisticated instruments nowadays, there are still problems as shown by discrepancies between different satellite products (Zhao et al., 2005). On the other hand, the ground-based aerosol remote
Aerosol optical properties

D. G. Kaskaoutis et al.

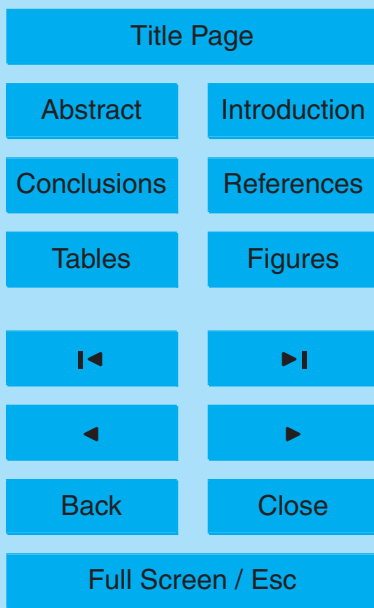

Printer-friendly Version

Interactive Discussion 
sensing does not provide complete global coverage. Nevertheless, the performance of surface based spectral measurements of sun and sky radiation is best suited for reliably and continuously deriving the aerosol optical properties. To this aim, worldwide efforts have been undertaken since the 1980s, and especially since the early 1990s, to 5 establish ground-based networks (e.g. Aerosol Robotic Network, AERONET) for monitoring the aerosol optical properties in selected key locations. In spite of the incomplete global coverage of surface measurements, and the high temporal and spatial aerosol variability, there is a rather limited number of general categories of aerosol types with distinct optical properties. In general, aerosols can be classified into the following four 10 aerosol types, which are associated with different sources and emission processes, and they exhibit significantly different optical properties: 1) biomass-burning aerosols, produced by forest and grassland fires, 2) urban/industrial aerosols from fossil fuel combustion in populated urban/industrial regions, 3) desert dust blown into the atmosphere by wind, and 4) aerosols of maritime origin. Detailed knowledge of the optical 15 properties of these four key aerosol types is needed for deriving the respective radiative forcings (Dubovik et al., 2002). Beyond this, it is also important to improve the accuracy of satellite-retrieval algorithms, which rely on assumptions about the optical properties of different aerosol types (Kaufman et al., 1997; King et al., 1999).

The aerosol optical depth (AOD), which is the integral of the atmospheric extinction coefficient from the surface to the top of the atmosphere, is an important parameter for visibility degradation (due to atmospheric pollution), solar radiation extinction, climate effects, and tropospheric corrections in remote sensing (Dubovik et al., 2002). The AOD constitutes a unique parameter to remotely assess the aerosol burden in the atmosphere from ground-based equipment, which constitutes the simplest, most accurate, and easy to maintain monitoring system (Holben et al., 2001). Knowledge on the spectral dependence of AOD is important for adequately modeling the effects of aerosols on the radation budget of the Earth-atmosphere system or for accurately retrieving the aerosol optical parameters from satellite-remote sensors (Eck et al., 1999). The wavelength dependence of AOD varies between different aerosol types because of

Aerosol optical properties

D. G. Kaskaoutis et al.

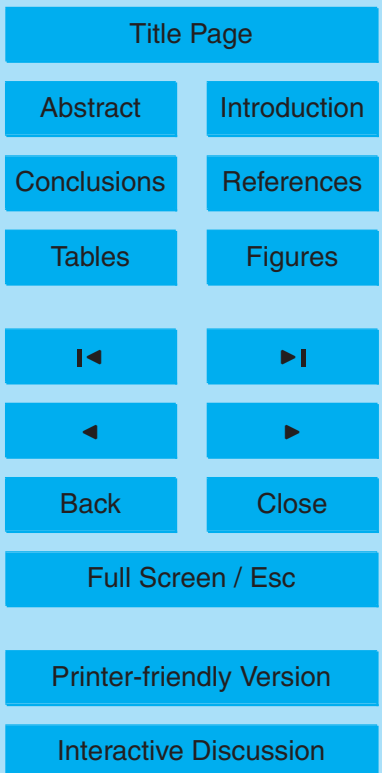

EGU 
their different physical and chemical characteristics. This AOD wavelength dependence is suitably expressed by the Ångström-exponent $\alpha$ (Angstrom, 1929). The derivation of $\alpha$ in different wavelength regions is a useful tool for distinguishing and characterizing the different aerosol types (Eck et al., 1999).

5 The use of Ångström exponent $\alpha$ has significantly increased in the last years, because this parameter is easily estimated using automated-surface sun photometry, while it is becoming increasingly accessible to satellite retrievals (Schuster et al., 2006). In addition to being a useful tool for extrapolating AOT throughout the shortwave spectral region, the value of Angstrom exponent is also a qualitative indicator of aerosol 10 particle size or fine mode fraction (Kaufman et al., 1994). Furthermore, there is also a relationship between this parameter and aerosol size distribution (Schuster et al., 2006). The $\alpha$ values have been used to characterize biomass burning aerosols in South America and Africa (Reid et al., 1999; Eck et al., 2001a, 2001b, 2003; Keil and Haywood, 2003), urban aerosols (Eck et al., 1999; Kaskaoutis and Kambezidis, 2006),

15 maritime aerosol component in islands (Smirnov et al., 2002; 2003) and desert-dust aerosols in Sahara and East Asia (Eck et al., 1999, 2005; Masmudi et al., 2003). Extensive analyses based on spectral aerosol measurements indicate that the Ångström exponent varies with wavelength, and that the spectral curvature of the least-squares fit to the Ångström exponent contains useful information about the aerosol size distribution (King and Byrne, 1976; O' Neill and Royer, 1993; Eck et al., 1999, 2001a, b, 2005; O' Neill et al., 2001a, b, 2003; Kaskaoutis and Kambezidis, 2006). Eck et al. (1999) established a curvature in the InAOD versus $\ln \lambda$ curve, which is very sensitive to the aerosol type and to the fine-to-coarse mode fraction. More recently, Schuster et al. (2006) explored the relationship between the spectral dependence of extinction and the size distribution of atmospheric aerosols. More specifically, they investigated the sensitivity of Angstrom exponent to both monomodal and bimodal aerosol size distributions by using multiwavelength Mie computations, and they explored the information content in the curvature of $\alpha$. They found that different values of the fine-mode fraction strongly modify the curvature changing its sign from negative to positive. Furthermore,

Aerosol optical properties

D. G. Kaskaoutis et al.

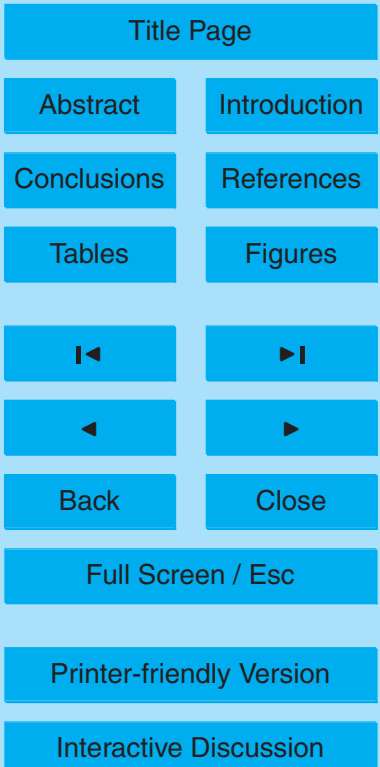

EGU 
they have shown that these theoretical Mie calculations were in agreement with AOD measurements from AERONET sites.

The present study focuses on the detailed investigation of the curvature effect of Ångström exponent for different aerosol types. This is essential since encountered 5 differences in the curvature of Ångström exponent of different aerosol types makes possible the discrimination between those aerosol types. The study is performed using data taken from four selected AERONET sites in key locations around the world, which are representative of different aerosol environments. This was shown in the work by Kaskaoutis et al., 2007) where the aerosol properties (AOD and $\alpha$ ) over the four 10 AERONET sites were characterized on an annual and seasonal basis. In this study, the main goal is to quantify the magnitude of the curvature for each aerosol type, and its relationship with the atmospheric turbidity and the Ångström exponent. The computations of the Angstrom exponent are performed at different wavelength pairs, as suggested by Schuster et al. (2006) in order to make possible qualitative assessments 15 about aerosol characterization. This aerosol characterization, based on the spectral dependence of AOD and $\alpha$, is useful for refining aerosol optical models, reducing uncertainties in satellite-aerosol observations and aerosol retrievals, and for improving the modeling of aerosol impacts on climate.

\section{Study regions and data used}

20 The AOD and Angstrom exponent values used in the present study were taken from four AERONET stations (Fig. 1) located in regions which are representative of four major aerosol regimes: biomass burning, urban, desert dust, and maritime. The stations are: a) Alta Floresta (Brazil), a rural site directly influenced by biomass burning smoke during the fire season (August-September), b) Ispra (Italy), an urban/industrial area with significant anthropogenic and industrial activities, c) Nauru, a remote island in the tropical Pacific characterized by very small aerosol loading, and d) Solar Village (Saudi Arabia), a continental remote site with significant contribution of desert parti-

Aerosol optical properties

D. G. Kaskaoutis et al.

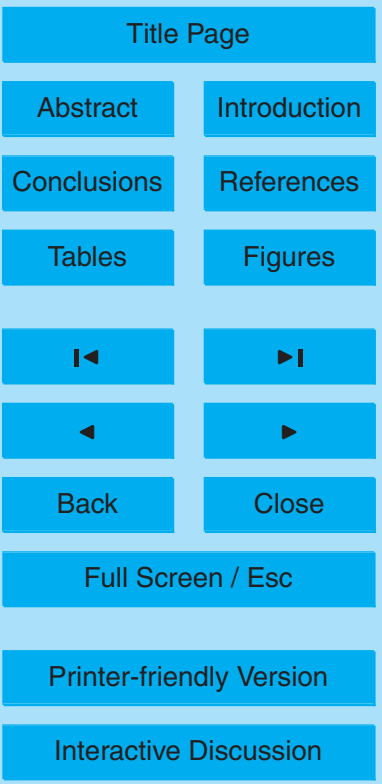

EGU 
cles. The AERONET data are provided in three categories: cloud contaminated (level 1.0 ), cloud-screened (level 1.5) following the methodology described by Smirnov et al. (2000), and cloud-screened and quality-assured (level 2.0). In this study, the level-2 daily mean cloud-screened data were used to ensure high quality. This, together with 5 the availability of enough (3-year) data, constituted the criterion for the selection of the four AERONET stations. More details on the characterization of aerosol particles at the four selected AERONET sites of the present work can be found in the study by Kaskaoutis et al. (2007).

The measurements reported in this paper were obtained with the CIMEL sun-sky 10 scanner spectral radiometers used in the AERONET global network. The instrumentation, data acquisition, retrieval algorithms, calibration procedure and accuracy are described in a series of papers (e.g. Eck et al., 1999, 2001a, b; Smirnov et al., 2000; Holben et al., 2001;) and therefore, only a brief description is given here. In brief, the solar extinction measurements taken every 15 minutes within the spectral range 15 340-1020 nm (Holben et al., 2001) are used to compute AOT at 340, 380, 440, 500, $675,870,970$ and $1020 \mathrm{~nm}$. Sky radiance almucantar measurements in conjunction with direct Sun measurements of AOT at $441,673,873$ and $1022 \mathrm{~nm}$ are used to retrieve columnar size distributions (from 0.05 to $15 \mu \mathrm{m}$ ), single scattering albedo, and refractive indices of the aerosols Dubovik and King (2000). The Angstrom parameter 20 is computed from AOT at the available wavelengths by AERONET. The overall uncertainty in AOT data, under cloud-free conditions, is \pm 0.01 for $\lambda>440 \mathrm{~nm}$, and \pm 0.02 for shorter wavelengths. The error in aerosol volume size distribution is estimated to be $\sim 15-25 \%$ for radii between 0.1 and $7 \mu \mathrm{m}$ (see Dubovik et al., 2000, 2002).

The period of measurements and the total number of daily values for each station 25 are given in Table 1. The larger number of data for Solar Village than for the other three stations is probably due to more stable and sunny weather in this site, permitting thus continuous measurements over long periods, especially in spring and summer. Given that sun-photometer measurements can be made only for meteorological conditions involving low-cloud cover or conditions in which the sun is visible through cloud gaps,

Aerosol optical properties

D. G. Kaskaoutis et al.

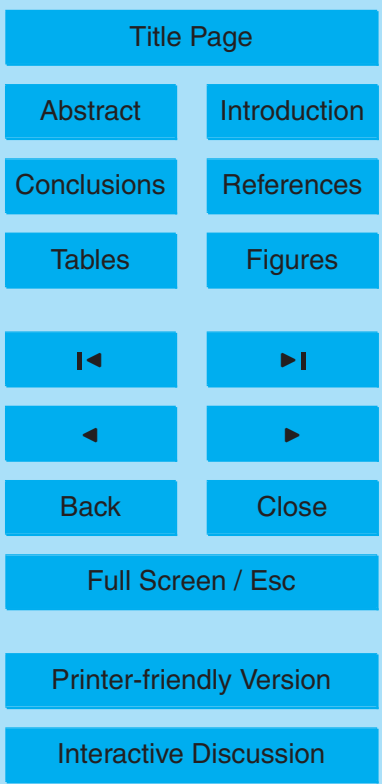

EGU 
the measurements are naturally biased towards atmospheric high-pressure systems. Therefore, in Alta Floresta and Ispra there are less measurements than in Solar Village, due to the smaller number of measurements during cloudy and rainy periods (winter), when the maximum rainfall and cloud cover occurs. It is likely that ground level in5 situ sampling performed on rainy days would record lower aerosol concentrations due to washout and wet deposition of aerosols and that this may result in lower seasonal mean concentrations during months of high rainfall. The number of measurements in Nauru is the smallest compared to other sites due to the rapid filter degradation occurring in harsh environmental conditions (sea salt, dust mixture and high humidity).

10 The number of data used allows the evaluation of the variability of AOD and Ångström exponent for the four sites. Note that care has been taken to ensure the representativity of the seasonal variation of aerosol properties (AOD and Ångström exponent) based on the criterion of existence of a minimum number of data for each season (16 to $36 \%$ of the total number of data, see Table 1).

\section{Theoretical background and methodology}

\subsection{Theoretical background}

Ångström (1929) proposed an empirical formula to approximate the spectral dependence of atmospheric extinction (scattering and absorption) caused by aerosols:

$\mathrm{AOD}_{\lambda}=\beta \lambda^{-\alpha}$

where $\mathrm{AOD}_{\lambda}$ is the approximated aerosol optical depth at the wavelength $\lambda, \beta$ is the Angstrom's turbidity coefficient which equals AOD at $\lambda=1 \mu \mathrm{m}$, and $\alpha$ is the widely known Angstrom exponent. Although in this definition $\alpha$ and $\beta$ are assumed independent to the wavelength, it is well known that both parameters depend on wavelength. Shifrin (1995) gave a general definition of the Ångström formula with Eq. (1) being a

ACPD

7, 7347-7397, 2007

Aerosol optical properties

D. G. Kaskaoutis et al.

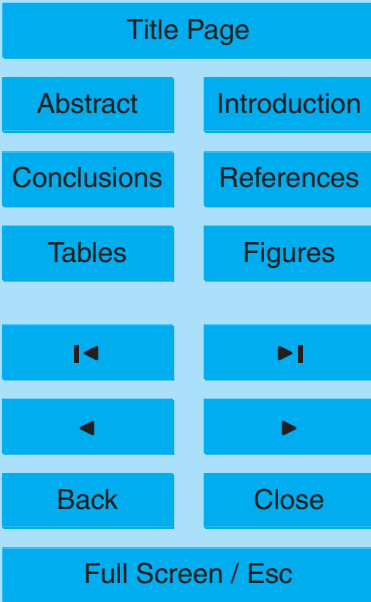

Printer-friendly Version

Interactive Discussion 
work by Cachorro et al. (2001). Junge (1955) was the first to explore a relationship between the Ångström exponent $\alpha$ and the aerosol size distribution by assuming a power-law relationship for the number density $(\mathrm{N})$ of aerosols as function of radius $(\mathrm{r})$ :

$$
\frac{d N}{d(\ln r)}=c r^{-v}
$$

5 where $d N$ is the number concentration of particles with radii between $r$ and $r+d r$, and $c$ and $v$ are fitting parameters characterizing the size distribution. The exponent $v$ is determined by the slope of the radius- distribution curve and $c$ is a constant related to the total mass of particles and their physical characteristics. Using Mie theory for spherical particles in the range $0.1 \mu \mathrm{m}<r<1 \mu \mathrm{m}$, Junge (1955) was able to show that $\alpha \approx v$ -

102 for nonabsorbing aerosols with $\alpha>1$. Particles in smoky hazes over Brazil tend to display a single submicron mode, with count median diameter of $\sim 0.12-0.25 \mu \mathrm{m}$ and a volume median diameter of $\sim 0.25-0.34 \mu \mathrm{m}$ (Reid et al., 1998). In this size range a strong relationship is expected between $\alpha$ and $v$ (Tomasi et al., 1983). However, it has been suggested that a soil mode is sometimes present in the aerosol over Amazonia

15 (Artaxo et al., 1994; Remer, et al., 1998), which could reduce the relationship between $\alpha$ and $v$. Although there is not a unique relationship between $\alpha$ and $v$ for all submicron mode particles, for a single fine-mode aerosol type, such as that produced by biomassburning aerosols, $\alpha$ can be a useful indicator of changes in the size distribution of the smoke particles (Reid et al., 1999).

20 However, this approximation does not hold for small values of $\alpha(\alpha \leq 1.0)$ or for absorbing aerosols as shown by various studies (Junge, 1955; Tomasi et al., 1983; Dellago and Horvath, 1993; Cachorro and de Frutos, 1995). The results of these studies have shown that the Ångström formula is a special case of a more complicated law valid for a limited range of values on the diameter of particles and for a limited inter25 val of wavelengths. The validity of this theory presupposes that the Junge power law is valid for the particle-radius range, where significant extinction takes place and that the spectral variation of the refractive index does not impose significant variations on the Mie extinction factor. However, various works (King and Byrne, 1976) have shown

Aerosol optical properties

D. G. Kaskaoutis et al.

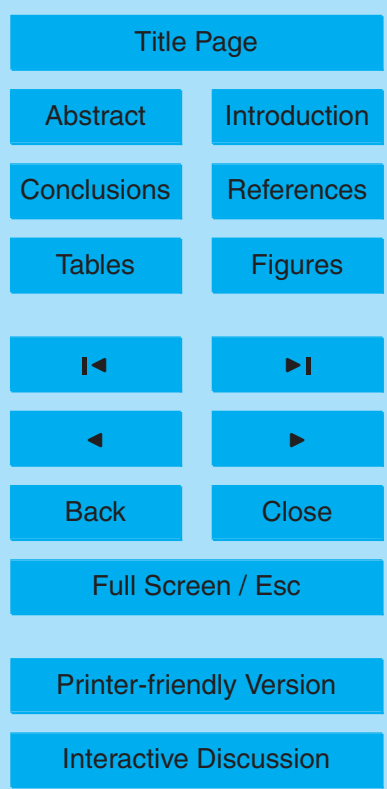


that the size distribution of aerosols does not typically follow the Junge power law. Moreover, King and Byrne (1976) have shown that aerosol size distributions do not have radii extending from zero to infinity, so that the departures from the above conditions introduce a curvature in the relationship between the logarithm of the spectral 5 aerosol optical depth and that of the wavelength. Consequently, Eq. (1) does not imply a straight line in logarithmic co-ordinates:

$\ln \mathrm{AOD}_{\lambda}=-\alpha \ln \lambda+\ln \beta$

By ratioing Eq. (3) at two different wavelengths and then taking the logarithm, the Angstrom exponent can be computed from spectral values of AOD as:

${ }_{10} \alpha=-\frac{d \ln \mathrm{AOD}_{\lambda}}{d \ln \lambda}$

The Ångström exponent itself varies with wavelength, and a more precise empirical relationship between aerosol extinction and wavelength is obtained with a second-order polynomial fit (King and Byrne, 1976; Eck et al., 1999, 2001a, b, 2005; O' Neill et al., 2001a, 2003; Pedrós et al, 2003; Kaskaoutis and Kambezidis, 2006):

$15 \ln \mathrm{AOD}_{\lambda}=\alpha_{o}+\alpha_{1} \ln \lambda+\alpha_{2}(\ln \lambda)^{2}$

where the coefficient $\alpha_{2}$ accounts for a curvature often observed in Sun photometry measurements. The second derivative is a measure of the rate of change of the slope with respect to wavelength. From Eq. (3) and the second order polynomial fit given by Eq. (5) the following relationship is obtained:

20 $\alpha=\frac{d \alpha}{d \ln \lambda}=-\frac{d\left(d \ln \mathrm{AOD}_{\lambda} / d \ln \lambda\right)}{d \ln \lambda}=-2 \alpha_{2}$

The curvature can be an indicator of the aerosol particle size, with negative curvature indicating aerosol size distributions dominated by the fine mode and positive curvature indicating size distributions with a significant contribution by the coarse mode (Eck et al., 1999, 2001b; Reid et al., 1999; Schuster et al., 2006).

ACPD

$7,7347-7397,2007$

Aerosol optical properties

D. G. Kaskaoutis et al.

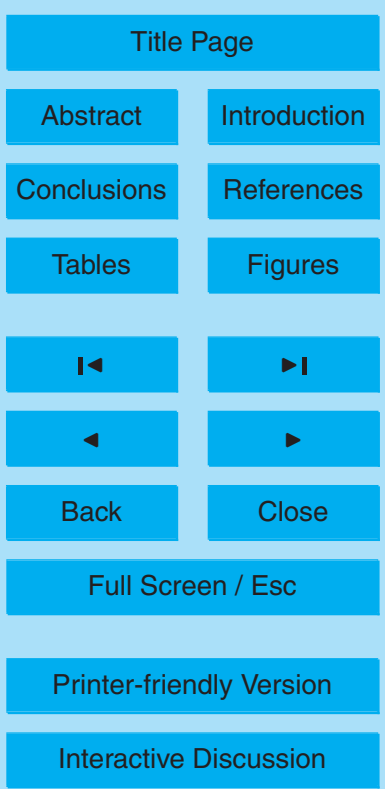




\subsection{Methodology}

In this study, the values of Ångström-parameter $\alpha$ were computed in the wavelength interval 440-870 nm, using the AOD data of the selected four AERONET sites, applying the least-squares method to Eq. (3) (Holben et al., 2001). The logarithmic linear fit is

5 the most precise method, although the results derived can also depend on the spectral interval considered (Pedrós et al., 2003). Thus, the same method was used for the computation of $\alpha$ in the spectral interval 340-870 nm, aiming to compare the $\alpha_{340-870}$ values with the $\alpha_{440-870}$ ones for different aerosol types. In addition, the Volz method (Eck et al., 1999, 2001a) has been applied for the computation of $\alpha$ in two narrow spectral intervals $(380-440 \mathrm{~nm})$ and $(675-870 \mathrm{~nm})$ using the AERONET AOD values at the corresponding wavelengths. Errors and uncertainties in the determination of $\alpha$ through the employed methods are reported by Pedrós et al. (2003).

The second-order polynomial fit (Eq. 5) was also applied to the AOD values at six wavelengths $(340,380,440,500,675$ and $870 \mathrm{~nm})$, although three of them are sufficient for this computation as indicated by Eck et al. (2001a). The second-order polynomial fit to the InAOD versus In $\lambda$ data has been shown to provide excellent agreement with measured $A O D_{\lambda}$, involving differences of the order of the uncertainty in the measurements, opposite to the linear fit to $\ln A O D$ versus $\ln \lambda$, which yields significant differences with measured AOD (e.g. Eck et al., 1999; 2001a; Kaskaoutis and Kambezidis, 2006). Almost in all cases of the present study, the second order fit provides an excellent agreement with measured AOD (coefficient of determination $R^{2} \geq 0.98$ ), although at Nauru the $R^{2}$ values range between $\sim 0.7$ and 0.98 . The errors of these computations are further investigated in Sect. 4.4. Further, through the least-squares method, the $\alpha$ values were computed in the spectral region $340-870 \mathrm{~nm}$ using the AOD values at 256 wavelengths. Note that the AODs at $1020 \mathrm{~nm}$ were not included in the linear and second-order polynomial fits in this work because of possible water-vapor absorption effects at that wavelength, resulting in inaccuracies in the computations of the secondorder polynomial fit and the estimations of the parameters $\alpha_{1}$ and $\alpha_{2}$ (see e.g. Eck et

Aerosol optical properties

D. G. Kaskaoutis et al.

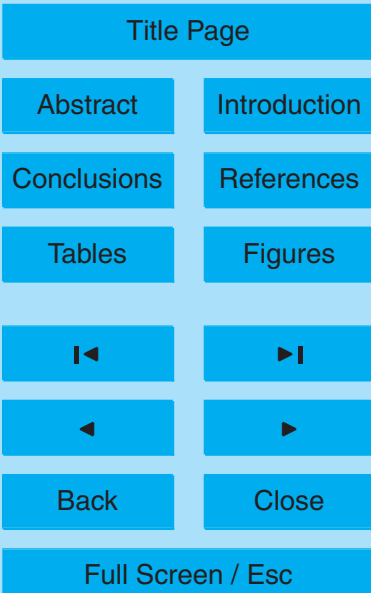

Printer-friendly Version

Interactive Discussion 
al., 2001a). The uncertainties in the AOD retrievals at $1020 \mathrm{~nm}$ are greater than for the other non-UV wavelengths since the CIMEL silicon detector is temperature-sensitive at that wavelength $\left(\sim 0.25 \%{ }^{\circ} \mathrm{C}\right)$ (Eck et al., 2001a). Therefore, the inclusion of the AODs at $1020 \mathrm{~nm}$ in the computations of the second-order polynomial fit and the estimations 5 of the parameters $\alpha_{1}$ and $\alpha_{2}$ causes more inaccuracies in the estimations. Possible reasons for these inaccuracies are described in detail by Eck et al. (2001a). Henceforth the $\alpha$ values are referred to $440-870 \mathrm{~nm}$ (AERONET $\alpha$ ), while the curvature is computed in the spectral interval $340-870 \mathrm{~nm}$. Whenever different wavelength regions are used in the computations, these will be reported at each instance.

\section{Results and discussion}

\subsection{Spectral dependence of Angstrom exponent $\alpha$}

In this section, there are given the results of our analysis of the spectral dependence of $\alpha$ and its relationship with atmospheric turbidity. To accomplish this, the values of $\alpha$ were computed in two narrow spectral intervals, $380-440 \mathrm{~nm}$ and $675-870 \mathrm{~nm}$ by applying the Volz method. The correlation between $\alpha$ values computed in short-andlong wavelength bands, which do not overlap with each other, are given in Fig. 2 for the four selected representative AERONET sites. Given the different type of aerosols at each site (see Sect. 2 and Kaskaoutis et al., 2007) the results of Fig. 2 shed light on the relationship between the spectral dependence of $\alpha$ and the aerosol type. We recall that the traditional power law for aerosol extinction is a purely empirical relationship (Eq. 1), and that the second-order polynomial (Eq. 5) describes more accurately the wavelength dependence of aerosol extinction.

The points above and below the one-to-one line correspond to negative and positive $\alpha_{2}$ values, respectively. In case of negative curvature $\left(\alpha_{2}<0\right.$, convex type curves) the rate of change of $\alpha$ is more significant at the longer wavelengths, while in case of positive curvature ( $\alpha_{2}>0$, concave type curves) the rate of change of $\alpha$ is more signif-

Aerosol optical properties

D. G. Kaskaoutis et al.

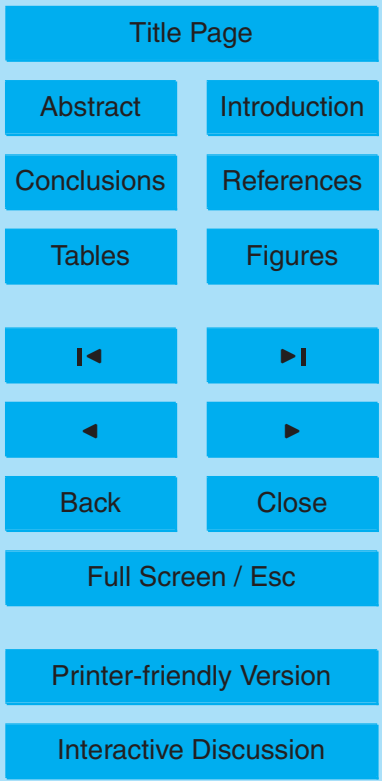

EGU 
icant at the shorter wavelengths. Eck et al. (1999) reported the existence of negative curvatures for fine-mode aerosols and positive curvatures for significant contribution by coarse-mode particles in the size distribution. According to our results, in all sites the regression between $\alpha$ in the two spectral intervals is not linear, as evidenced by 5 the very small fraction of total points lying on the one-to-one line. Points located in the upper parts of the plots (negative curvature, $\alpha_{2}<0$ ) indicate the presence of fine-mode aerosols; this is mainly the case in Alta Floresta and Ispra stations. Indeed, our analysis (see Kaskaoutis et al., 2007) has shown that biomass burning or urban fine aerosols are present in the atmosphere of these two stations in about $50 \%$ on a year basis, and 10 even more frequently in summer and autumn. Schuster et al. (2006) indicated that negative curvatures can exist even for fine-mode volume fraction equal or less than 0.5. They also reported that the curvature decreases (i.e. approaches linearity) as the fine-mode particle size increases, while negative curvature can also occur even in the presence of a significant coarse-mode component. The curvature in Ispra is negative ${ }_{15}\left(\alpha_{2}<0\right)$ in $58 \%$ of total cases, against $40 \%$ for Alta Floresta, whereas in the rest two stations, Nauru and Solar Village, the curvature is rarely negative. Indeed, the values of $\alpha_{2}$ are positive in $97.5 \%$ and $87.5 \%$ of the cases, in Nauru and Solar Village, respectively, indicating a strong contribution by the coarse-mode aerosols. These aerosols, as shown by Kaskaoutis et al. (2007) are of maritime or desert dust, respectively.

The correlation coefficients between the $\alpha$ values of Angstrom exponent computed at shorter $(380-440 \mathrm{~nm})$ and longer $(675-870 \mathrm{~nm})$ wavelengths for the four sites are given below:

$$
\begin{aligned}
\alpha_{675-870} & =-0.46(0.07) \alpha_{380-440}+1.74(0.11) R^{2}=0.06 \text { (AltaFloresta) } \\
\alpha_{675-870} & =0.34(0.04) \alpha_{380-440}+1.04(0.06) R^{2}=0.08 \text { (Ispra) } \\
{ }_{25} \quad \alpha_{675-870} & =0.15(0.02) \alpha_{380-440}-0.23(0.38) R^{2}=0.14 \text { (Nauru) } \\
\alpha_{675-870} & =0.39(0.02) \alpha_{380-440}+0.17(0.02) R^{2}=0.39 \text { (SolarVillage) }
\end{aligned}
$$

\section{Aerosol optical properties}

D. G. Kaskaoutis et al.

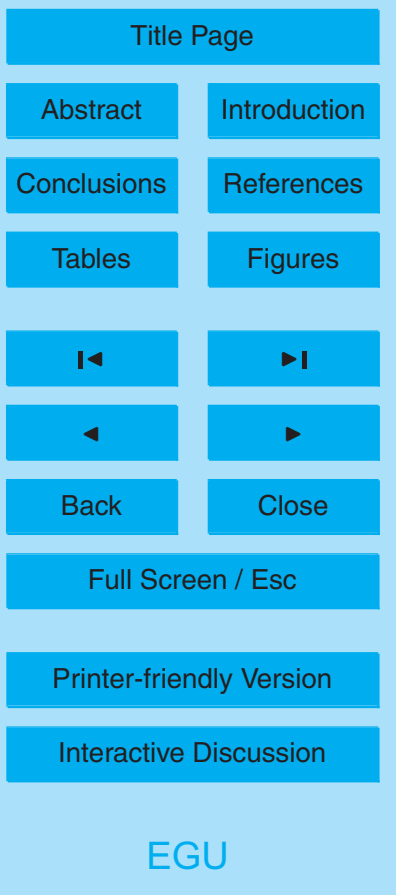


Our results indicate that there exist large differences between $\alpha$ values computed in narrow spectral bands at shorter and longer wavelengths. These differences depend strongly on the selected wavelength interval and the computation method used (e.g. Cachorro et al., 2001; Pedrós et al., 2003; Kaskaoutis and Kambezidis, 2006).

5 Furthermore, no correlation was found between the curvature and the $\alpha_{675-870} / \alpha_{380-440}$ values at all stations. Therefore, it is concluded that the curvature does not depend on the slope of the straight line of InAOD versus $\ln \lambda$ considered in narrow spectral bands either at shorter or longer wavelengths. On the contrary, the curvature does depend on the differences in $\alpha$ computed at shorter and longer wavelengths.

10 In Fig. 2, for each station, the mean and standard deviation values of Angstrom exponent are also given. Based on the computed $\alpha$ values, the four AERONET sites can be divided in two categories: i) Alta Floresta and Ispra stations and ii) Nauru and Solar Village stations. The $\alpha_{675-870}$ values of the first group are larger or slightly smaller than the $\alpha_{380-440}$ ones, while in the second group they are clearly smaller. 15 Note that the larger mean $\alpha_{380-440}$ than $\alpha_{675-870}$ values in Alta Floresta are due to the existence of very small (negative) $\alpha_{675-870}$ values. According to our analysis, these values correspond to $\mathrm{AOD}_{500}<0.1$, not representing biomass-burning conditions. In contrast, for $\mathrm{AOD}_{500}>0.5$, the $\alpha_{675-870}$ values are significantly larger than $\alpha_{380-440}$. Thus, we can generalize the statement concerning the 1st group of stations, saying that for this group the $\alpha_{675-870}$ values are larger than the $\alpha_{380-440}$ ones. On the other hand, in the $2^{\text {nd }}$ group of stations, i.e. Nauru and Solar Village, the values of $\alpha_{675-870}$ are smaller than. $\alpha_{380-440}$. Yet, in Nauru there are very large differences, owing to some very large $\alpha_{380-440}$ values; which according to our analysis are attributed to significantly larger $\mathrm{AOD}_{380}$ than $\mathrm{AOD}_{440}$ values. In contrast, at the long wavelengths, the mean ${ }_{25} \alpha_{675-870}$ value is negative, associated with negative values in the majority of cases, especially for very small $\mathrm{AOD}_{500}$ values. In Solar Village, the $\alpha_{380-440}$ and $\alpha_{675-870}$ values correlate well for $\alpha_{380-440}<0.5$, but not for $\alpha_{380-440}>1.0$.

The spectral variation of Angstrom exponent $\alpha$ is strongly dependent on the atmospheric turbidity and aerosol type. In Fig. 3, the differences between the values of

Aerosol optical properties

D. G. Kaskaoutis et al.

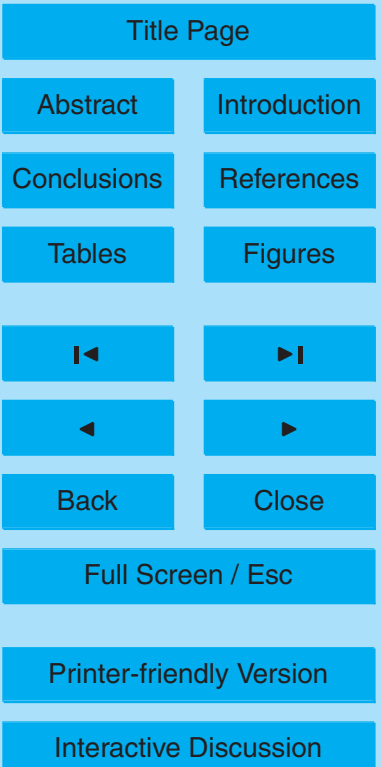


$\alpha_{380-440}$ and $\alpha_{675-870}$ are displayed as function of atmospheric turbidity by means of $\mathrm{AOD}_{500}$. Positive and negative differences are indicative of positive and negative curvatures, respectively, while differences near zero indicate the absence of spectral variability in the Angstrom exponent. A common feature in all sites is the very large range 5 of differences for small $A O D_{500}$, against decreasing magnitude of differences with increasing $\mathrm{AOD}_{500}$. In Alta Floresta, as the $\mathrm{AOD}_{500}$ increases, i.e. under heavy turbid conditions from biomass smoke, the differences are negative $\left(\alpha_{675-870}\right.$ is greater than $\left.\alpha_{380-440}\right)$. This confirms that for fine-mode particles, under turbid conditions, the curvature becomes negative. In Ispra, similarly to Alta Floresta, for moderate-to-low $\mathrm{AOD}_{500}$, 10 the differences $\alpha_{380-440}-\alpha_{675-870}$ are either positive or negative to similar percentages. In contrast, for $\mathrm{AOD}_{500}>0.7$ the differences are always negative, indicating thus larger fine-mode fraction, mainly of industrial origin. As far as it concerns Nauru, there are generally large positive differences over the entire range of AOD values, indicating a significant spectral variation of $\alpha$ at any $\mathrm{AOD}_{500}$ in this remote oceanic location. In 15 Solar Village, the differences are positive in most cases, while they tend to zero for higher $\left(\mathrm{AOD}_{500}>0.5\right)$ values, associated with turbid dust conditions. Our results are in agreement with Eck et al. (1999) who noticed a rather negligible spectral variation of $\alpha$ for high turbid conditions in arid environments. On the other hand, they reported that higher AODs accompanied with aerosol size distributions with a significant fine mode fraction (smoke events) enhanced the spectral variation of $\alpha$ in agreement with our results. Note that Kaskaoutis and Kambezidis (2006) reported also a small spectral variation of $\alpha$, and therefore, small curvature under turbid conditions in Athens. On the other hand, the correlations between the differences and the values of $A O D_{500}$ exhibit significant scatter.

25 Based on the results of Fig. 2, it has been stated that in case of $\alpha_{380-440}>\alpha_{675-870}$ the curvature $\alpha_{2}$ is positive. Therefore, positive and negative differences $\alpha_{380-440}$ $\alpha_{675-870}$ in Fig. 3 should correspond to positive and negative curvatures $\left(\alpha_{2}\right)$, respectively. According to this, it is expected that the scatter diagram (Fig. 4), which correlates the differences $\alpha_{380-440}-\alpha_{675-870}$ with $\alpha_{2}$ values computed with Eq. (5), must
Aerosol optical properties

D. G. Kaskaoutis et al.

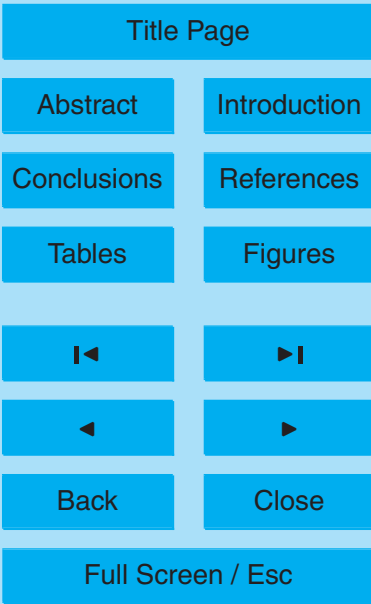

Printer-friendly Version

Interactive Discussion 
include data points only in the first and third quadrant. However, the results for the four AERONET sites exhibit a significant departure from this behaviour. This deserves further investigation to identify possible reasons.

In Alta Floresta it is found that $15 \%$ and $26 \%$ of total number of data pairs lie in 5 the second and quarter quadrant, respectively. The corresponding percentages for the stations of Ispra, Nauru, and Solar Village are equal to $4 \%, 2 \%$, and $6 \%$ for the 2nd quadrant, and $17 \%, 6 \%$, and $3 \%$ for the 4th quadrant. Our analysis shows that the majority of these cases, especially for Alta Floresta and Ispra, correspond to small magnitudes of both $\alpha_{2}$ and $\alpha_{380-440}-\alpha_{675-870}$. Nevertheless, there are some cases 10 with large absolute values. These latter cases correspond to larger uncertainties in the applied polynomial fit $\left(R^{2}<0.94\right)$. Therefore, the departure from the behaviour according to which positive/negative curvatures are associated with positive/negative differences $\alpha_{380-440}-\alpha_{675-870}$, can be attributed to the fact that the polynomial fit associated with $\alpha_{2}$ does not cover the same spectral range, since it includes the AOD values at $15340 \mathrm{~nm}$. It is probable that the inclusion of $\mathrm{AOD}_{340}$ in the polynomial fit strongly affects the computed $\alpha_{1}$ and $\alpha_{2}$ values, resulting in significant errors.

To verify this, the computations of $\alpha_{2}$ values were repeated using the polynomial fit, but in the $380-870 \mathrm{~nm}$ spectral range instead of $340-870 \mathrm{~nm}$, and the results are given in Fig. 4b. Obviously, the change of spectral range for the computation of $\alpha_{2}$ 20 results in largely different results; almost no data point are found in the second and fourth quadrant anymore. Moreover the scatter of points is drastically reduced by not considering the AOD values at $340 \mathrm{~nm}$ in terms of the polynomial fit. Consequently, the statement that the positive or negative $\alpha_{2}$ are associated with respective spectral differences in the values of Angstrom exponent $\alpha$, derived from the results of Figs. 2 25 and 3, and also reported by Schuster et al. (2006) has to be supplemented by that it is valid only when consistent spectral intervals are used in the computation of the polynomial fit.

The values of the second derivative of $\alpha$ (Eq. 6) computed from the polynomial fit to the AOD values at $340,380,440,500,675$ and $870 \mathrm{~nm}$ as a function of $A O D_{500}$

Aerosol optical properties

D. G. Kaskaoutis et al.

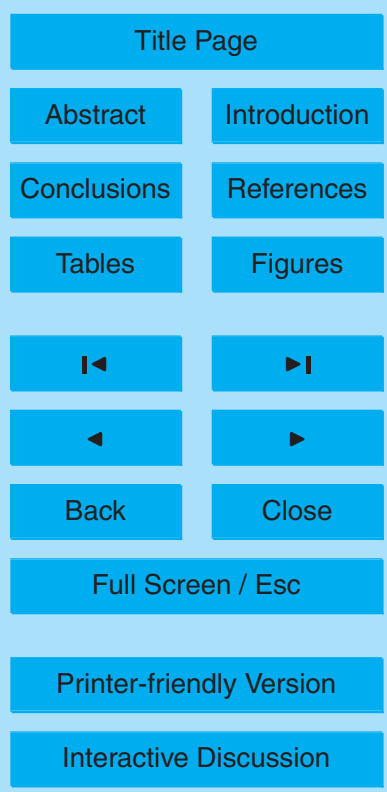

EGU 
are depicted in Fig. 5 for the four selected AERONET sites. Positive values of typically occur in predominately fine-mode bimodal size distributions with the value of increasing as the fine-mode increasingly dominates over the coarse-mode ones (Eck et al., 1999; Reid et al., 1999; O' Neill et al., 2001a). Large positive values of are char5 acteristic of fine-mode dominated aerosol size distributions (Eck et al., 1999, 2001b), while near zero and negative values of are characteristic of size distributions with a dominant coarse-mode or bimodal distributions with coarse-mode aerosols having a significant relative magnitude (Eck et al., 1999; O' Neill et al., 2001a; Kaskaoutis and Kambezidis, 2006). Indeed, in Alta Floresta and Ispra, i.e. sites which are charac10 terized by fine-mode biomass burning and urban aerosols (Kaskaoutis et al., 2007), there is a tendency toward larger positive values of , especially as $A_{0 D} D_{500}$ increases, due to the strong optical influence of fine-mode particles at the higher optical depths. Therefore, positive values typically occur in predominately fine-mode bimodal size distributions with the value of increasing as the fine-mode increasingly dominates over the 15 coarse-mode ones (Eck et al., 1999; Reid et al., 1999; O' Neill et al., 2001a). On the contrary, Solar Village has values near zero or slightly negative, indicating the presence of coarse particles, which is the case since this site has a strong influence of desert dust. Near-zero or slightly negative values associated with desert dust, have been also reported by Eck et al. (1999) and O' Neill et al. (2001a). Note that negative values 20 (down to -4) are also found in Nauru, which are associated with maritime coarse particles. The use of polynomial fit is important since in cases with positive , the application of a simple linear Ångström fit to the InAOD versus $\ln \lambda$ for all wavelengths, results in an overestimation of AOD at the short and long wavelengths, against an underestimation at the middle wavelengths, and vice-versa for negative (Eck et al., 1999, 2001a; 25 Kaskaoutis and Kambezidis, 2006). Only when is equal to zero, there is no curvature in the InAOD versus In $\lambda$ relationship and, therefore, the Ångström formula fits the AOD data adequately. However, this is not the case, as indicated by the relatively large scatter of values. The largest departure from linearity in the $\ln A O D$ versus $\ln \lambda$ relationship appears for Nauru. This is in agreement with the results by Eck et al. (2001b) according

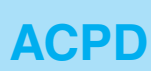

$7,7347-7397,2007$

Aerosol optical properties

D. G. Kaskaoutis et al.

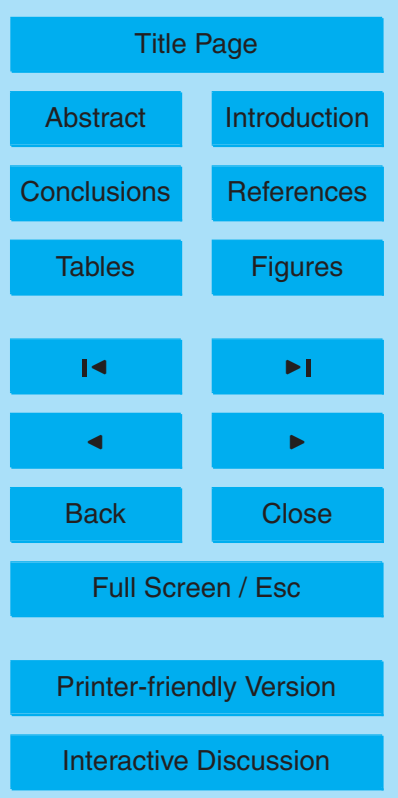

EGU 
to which the largest departures exist for weakly absorbing aerosols and/or aerosols having relatively large-size accumulation mode.

For small aerosol optical depths at $500 \mathrm{~nm}$ there is a large range of values, both negative and positive (from -5 to 2 ). This is an indication of the existence of bimodal-

5 size distributions at relatively low optical depths, with fine-mode particles determining the wavelength dependence of AOD at the shorter wavelengths, and coarse-mode particles similarly the wavelength dependence at longer wavelengths ( $O$ ' Neill et al., 2001a). The large negative values for very small AODs indicate a significant departure from linearity (Eq. 3) under clean atmospheric conditions. Such a departure was re10 ported by Kaskaoutis and Kambezidis (2006) for an urban site (Athens), while in this work is found to occur at other aerosol environments as well, i.e. clean maritime, desert and biomass burning. A similar relationship between AOD and has been also reported in several studies (Eck et al., 1999, 2001a, b, 2003, 2005) for different aerosol types (e.g. biomass-burning, urban/industrial, desert dust). Note that the negative values at 15 the small AODs, associated mainly with coarse desert-dust and sea-salt particles, approach zero as $A O D_{500}$ increases, in contrast to the positive values (fine particles, Alta Floresta and Ispra) not approaching zero with increasing $\mathrm{AOD}_{500}$.

\subsection{The second-order polynomial fit}

In this section, the coefficients $\alpha_{1}$ and $\alpha_{2}$ obtained through application of the 2nd20 order polynomial fit in the spectral region $340-870 \mathrm{~nm}$ are further analyzed for the four representative AERONET sites. More specifically, they are correlated with the AERONET $\alpha$ and $\mathrm{AOD}_{500}$ values.

These coefficients exhibit a wide range of values in each site proportionally to the dominant aerosol type. Therefore, their values exhibit strong seasonal variation, es25 pecially in sites where a specific aerosol type dominates over specific time periods (e.g. biomass burning in Alta Floresta in August-September and desert dust in Solar Village in May). The monthly means, and the associated standard deviations of $\alpha_{1}$ and $\alpha_{2}$ are shown in Figs. 6 and 7, respectively, along with the corresponding yearly

Aerosol optical properties

D. G. Kaskaoutis et al.

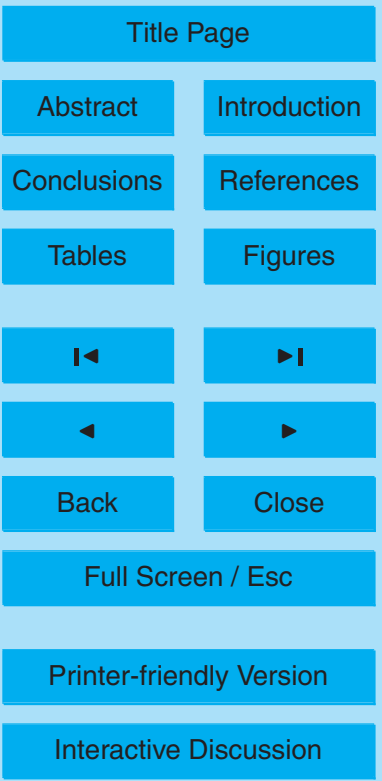


values. In all sites, except for Nauru, the $\alpha_{1}$ values are mostly negative, as expected. The annual cycle of $\alpha_{1}$ in Alta Floresta, Ispra, and Solar Village, exhibits larger values in summer and autumn and lower in winter and spring. This is mainly attributed to the dominant aerosol type at each site, i.e. biomass smoke in Alta Floresta and ur5 ban in Ispra (highly negative $\alpha_{1}$, especially during summer and autumn, respectively) and desert dust in Solar Village ( $\alpha_{1}$ near zero, especially in spring). However, the annual cycle in Ispra is not too distinct. The near-zero $\alpha_{1}$ in January and February is attributed to some positive $\alpha_{1}$ values in these months in Solar Village. In Nauru, there is a large month-to-month variability, resulting in the absence of a clear annual cycle. 10 This variability is due to the concurrent presence of positive and negative $\alpha_{1}$ values.

The seasonal variation of $\alpha_{2}$ (Fig. 7) permits an assessment about the dominance of fine-or coarse-mode aerosols for each month and site. The small mean annual values in Alta Floresta and Ispra (0.004 and -0.07 , respectively) do not involve small curvatures, since they result from both positive and negative values (ranging from about $15-0.6$ to 0.4 ). In Alta Floresta, negative $\alpha_{2}$ values occur from June to November, due to the predominance of fine-mode smoke particles (see also Kaskaoutis et al., 2007), whereas positive $\alpha_{2}$ values occur in the rest of the year, i.e. when there is also influence of coarse-mode particles mainly of maritime origin. In Ispra, negative $\alpha_{2}$ values persist from March to November, associated with urban fine-mode aerosols, against positive values in the rest of the year. However, the standard deviations indicate that in all months but November and December, both positive and negative curvatures exist. In Nauru and Solar Village, the significant contribution of coarse-mode sea-salt and desert-dust aerosols, respectively, throughout the year (Kaskaoutis et al., 2007) leads to positive mean $\alpha_{2}$ values over all months.

25 In Fig. 8, the coefficient $\alpha_{1}$ is correlated with $\mathrm{AOD}_{500}$ for each site. In Alta Floresta, Ispra, and Solar Village the $\alpha_{1}$ values are mostly negative, as expected $\left(\alpha_{1} \sim-\alpha\right)$. On the contrary, this is not the case for Nauru (a site with clear atmospheric conditions, $\left.\mathrm{AOD}_{500}<0.18\right)$, where in the majority of cases $(75.9 \%) \alpha_{1}$ is positive. In Alta Floresta and Ispra only 7 and 9 cases, respectively, exhibit positive $\alpha_{1}$, whereas in So-

Aerosol optical properties

D. G. Kaskaoutis et al.

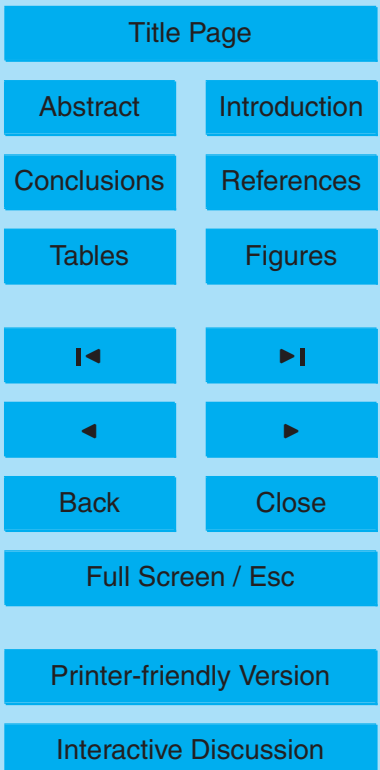

EGU 
lar Village, the $13.2 \%$ of total $\alpha_{1}$ values are positive. For all three sites (Alta Floresta, Ispra, and Solar Village) the positive $\alpha_{1}$ values appear under low-turbidity conditions $\left(\mathrm{AOD}_{500}<0.5\right)$. Our analysis has shown that the positive $\alpha_{1}$ values in Alta Floresta and Ispra are associated with significant uncertainties in the polynomial fit, $R^{2}<0.92$, result5 ing in large errors in the determination of both $\alpha_{1}$ and $\alpha_{2}$. Besides, the linear fit in these cases is highly inaccurate and therefore, the Angström formula is unable to describe the spectral variation of the AOD (Kaskaoutis et al., 2006). Note also the wide range of $\alpha_{1}$ for small $\mathrm{AOD}_{500}$ values against a reduction of this range with increasing $\mathrm{AOD}_{500}$.

The correlation between $\alpha_{2}$ and $\mathrm{AOD}_{500}$ (Fig. 9) provides information on the atmospheric conditions under which the spectral variation of $\alpha$ is negligible, so the spectral variation of AOD can be accurately described by the simple Angström formula $\left(\alpha_{1}=\right.$ $-\alpha$ ). The data lying on or near the $\alpha_{2}=0$ line correspond to bimodal lognormal aerosol size distributions without curvature. Based on the results of Fig. 9, it can be stated that in general, the error in using the simple linear fit becomes smaller with increasing tur15 bid atmospheric conditions, especially for maritime and desert aerosol environments (Nauru and Solar Village). Moreover, it is interesting to note the existence of negative curvatures in sites characterized by aerosol size distributions dominated by the coarsemode, i.e. desert-dust and sea-salt in Solar Village and Nauru, respectively, and also the occurrence of positive curvatures in sites characterized by aerosol size distributions dominated by fine-mode particles, in Alta Floresta and Ispra. Both cases occur mainly for low atmospheric turbidities. In all the four AERONET sites, there is a decreasing trend of $\alpha_{2}$ with increasing $\mathrm{AOD}_{500}$, in line with the results of Fig. 3. This is expected, since that the coefficient $\alpha_{2}$ is strongly correlated with the differences between $\alpha$ computed at shorter and longer wavelengths, as shown in Fig. 3. Nevertheless, the above relationship is weak, because of the significant scatter of data points, especially at low $\mathrm{AOD}_{500}$.

Based on the results of Fig. 9, it is possible to assume that there is negligible curvature within range $-0.01<\alpha_{2}<0.01$. In Alta Floresta, 14 cases, corresponding to $2.5 \%$ of total cases, fall into this interval. In Ispra and Solar Village, there are 13 and 16

Aerosol optical properties

D. G. Kaskaoutis et al.

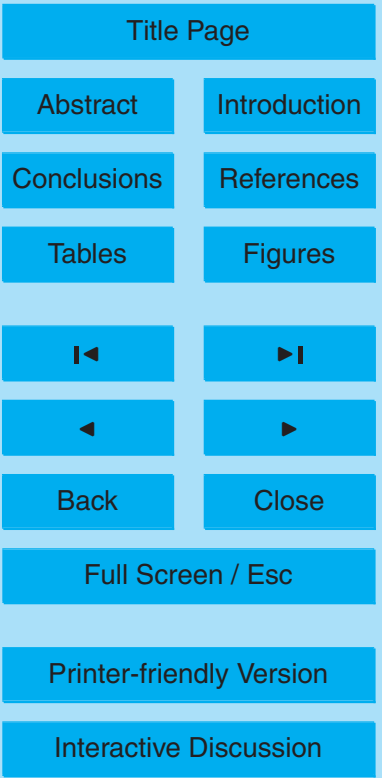

EGU 
cases, respectively, corresponding to $2 \%$ and $2.1 \%$ of total cases. For those cases, the linear fit (Eq. 3) is evaluated as greatly accurate $\left(R^{2}>0.98\right)$, while the relationship between $\alpha_{1}$ and $\alpha$ is very strong $\left(\mathrm{R}^{2}=0.82,0.85\right.$ and 0.96 for Alta Floresta, Ispra and Solar Village). Note that the very small $\alpha_{2}$ values do not occur for a specific $\mathrm{AOD}_{500}$ in5 terval; they appear for values of $\mathrm{AOD}_{500}$ ranging from 0.04 up to 0.55 . On the contrary, in Nauru none case satisfies the above criterion and, therefore, the curvature is always significant in this clean atmosphere. Below, we give the estimated equations relating $\alpha$ and $\alpha_{1}$, and the associated correlation coefficients:

$\alpha_{1}=--0.89(0.05) \alpha-0.11(0.12), R^{2}=0.82$ (AltaFloresta)

$\alpha_{1}=-1.13(0.03) \alpha+0.38(0.05), R^{2}=0.85$ (Ispra)

$\alpha_{1}=-0.96(0.03) \alpha-0.03(0.01), R^{2}=0.96$ (SolarVillage)

In Fig. 10, the correlation between the Angstrom exponent $\alpha$ (Eq. 3) and the coefficient $\alpha_{1}$ (Eq. 4) is displayed in a common diagram for the four representative AERONET sites. For intermediate values of $\alpha$, i.e. in cases of rather mixed aerosol types with particles originating from different source areas, the figure is zoomed for a clearer presentation. As expected, there is an anti-correlation between $\alpha$ and $\alpha_{1}$ in all sites, with a significant scatter. These anti-correlations were evaluated to be statistically significant at the $95 \%$ confidence level only in Alta Floresta and Ispra. Below, we give the estimated equations relating $\alpha$ and $\alpha_{1}$, and the associated correlation coefficients:

$\alpha_{1}=-1.44(0.05) \alpha+0.69(0.07), R^{2}=0.64$ (AltaFloresta)

$\alpha_{1}=-1.12(0.05) \alpha+0.26(0.08), R^{2}=0.44$ (Ispra)

$\alpha_{1}=-0.34(0.08) \alpha+0.43(0.04), R^{2}=0.04$ (Nauru)

$\alpha_{1}=-0.44(0.03) \alpha-0.01(0.02), R^{2}=0.22$ (SolarVillage)

Aerosol optical properties

D. G. Kaskaoutis et al.

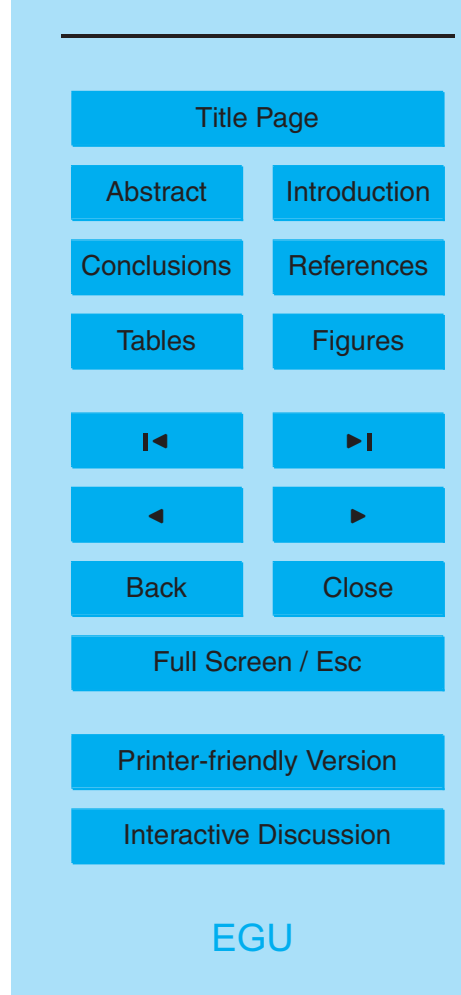


The relationship differs from a site to another, whereas it includes significantly larger errors and uncertainties than those for $\alpha_{2}$ values in the range \pm 0.01 , as expected. Definitely, the coefficient $\alpha_{1}$ is significantly different from $\alpha$, especially in the maritime and desert aerosol environments (Nauru and Solar Village, respectively). Consequently, 5 including spectral curvature in analyses enhance the knowledge about the volume fraction and effective radius of fine-mode aerosols at intermediate values of the Ångström exponent (Schuster et al., 2006).

The coefficient $\alpha_{s}$ computed in the spectral interval 340-870 nm versus the Angstrom exponent $\alpha_{440-870}$ is given in Fig. 11 for the four representative AERONET sites. Obvi10 ously, for a specific value of $\alpha_{440-870}$, a great range of $\alpha_{2}$ occurs. This is in agreement with the findings of Schuster et al. (2006), who showed that different size distributions with the same $\alpha$ can produce large differences in curvature, and verifies that solely curvature is not enough for describing aerosol particle size, as stated previously (e.g. Eck et al., 1999, 2001b; Reid et al., 1999). Yet, it is possible to discriminate between dif15 ferent aerosol types by plotting $\alpha$ vs $\alpha_{2}$. This is more clearly shown in the zoomed scatterplot for intermediate values of $\alpha_{440-870}$. Thus, the maritime aerosols (in blue) can be clearly identified, since they have large positive $\alpha_{2}$ values, while the desert dust particles (in yellow) have also positive values of $\alpha_{2}$, but with smaller magnitude (mostly <0.6). Within the $\alpha_{440-870}$ interval $0.5-1.5$, the biomass burning and the urban aerosols exhibit both positive and negative $\alpha_{2}$ values; this is because they have bimodal distributions with significant coarse fraction due to coagulation, condensation, gas-to-particle conversion and humidification processes (e.g. Eck et al., 2005). Cases with negative curvatures are associated with high fine-mode volume fractions, while positive curvatures are related with low fine-mode fractions at these intermediate values of $\alpha$, in agreement with Schuster et al. (2006).

However, the discrimination of aerosols is difficult in some cases. For example, for $\alpha_{440-870}<1.0$ it is hard to discriminate between biomass-burning or urban aerosols and the desert dust particles. This is due to the fact that the former particles are quite large in size, because of swelling of water vapor and aging processes, exhibiting thus similar

Aerosol optical properties

D. G. Kaskaoutis et al.

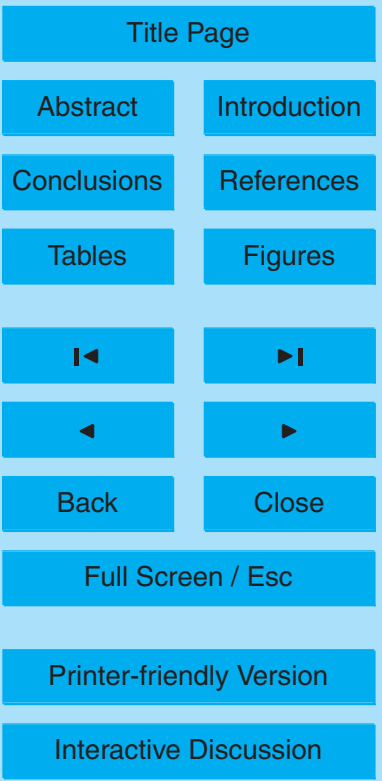


characteristics to the latter particles produced in arid areas. Nevertheless, despite this, our results indicate that in general, plotting $\alpha$ vs $\alpha_{2}$, is useful for discriminating between different aerosol types. Thus, curvature can be used to improve the information about aerosol size distributions and types at intermediate values of $\alpha$, as stated by Schuster 5 et al. (2006).

For aerosols dominated by large particles (sea salt, desert dust) there is a trend of increasing $\alpha_{2}$ with $\alpha$, while the opposite exists for aerosols with a large fine fraction (biomass burning, urban). Especially in Alta Floresta, for $\alpha$ values above 1.8 almost all $\alpha_{2}$ are negative implying negative curvatures for the fine-mode aerosols. In contrast, 10 positive $\alpha_{2}$ values are usually expected for moderate to low $(<1.3) \alpha$ values, probably aged smoke or mixed aerosols with a significant coarse fraction. Mie calculations (Schuster et al., 2006) indicate that increasing the concentration of coarse-mode particles reduces the Ångström exponent and dampens its sensitivity to the fine-mode effective radius. As a consequence, for lower $\alpha$ values the curvature can be positive or negative exhibiting larger scatter especially in Ispra. Nevertheless, the correlations between $\alpha$ and $\alpha_{2}$ given in the following expressions are not statistically significant and have high scatter.

$\alpha_{2}=-0.48(0.04) \alpha+0.69(0.05), R^{2}=0.25$ (AltaFloresta)

$\alpha_{2}=-0.22(0.04) \alpha+0.26(0.05), R^{2}=0.04$ (Ispra)

$\alpha_{2}=0.37(0.03) \alpha+0.05(0.02), R^{2}=0.18$ (SolarVillage)

The Ångström formula (Eq. 1) refers to the extinction of aerosols (scattering and absorption). Therefore, the question arises: how much can the absorption efficiency affect the Ångström exponent? This is significant for the accuracy of the above computations. Schuster et al. (2006) examined the sensitivity of $\alpha$ to the imaginary part of aerosol refractive index, and found that it was negligible for aerosols with low finevolume fractions. This is because the spectral dependence of absorption is similar

Aerosol optical properties

D. G. Kaskaoutis et al.

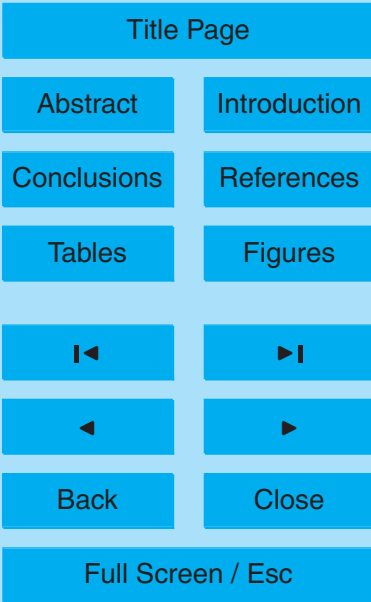

Printer-friendly Version

Interactive Discussion 
to the spectral dependence of extinction for coarse-mode particles and, therefore, the bulk-absorption coefficient has little effect on the extinction exponent of these particles. However, the bulk-absorption coefficient does have an impact on the Ångström exponent for large-volume fraction of fine-mode aerosols, although this sensitivity is small 5 and does not affect the $\alpha$ values and the above regressions.

Significant information about aerosol types and size distribution can be deduced from the correlation between the coefficients $\alpha_{1}$ and $\alpha_{2}$ (Fig. 12). Similar distributions based on both theoretical computations and experimental data, have been shown by Schuster et al. (2006). The results of Fig. 12 reveal the possibility of clearly discriminating 10 between different aerosol types, and they are in agreement with the findings of Schuster et al. (2006). Large negative $\alpha_{1}$ and $\alpha_{2}$ values correspond to biomass-burning or urban/industrial fine-mode aerosols (Alta Floresta and Ispra, respectively), while positive $\alpha_{2}$ and near zero or positive $\alpha_{1}$ values are indicative of large particles (desert dust, sea salt for Solar Village and Nauru, respectively). Note that there are positive $\alpha_{1}$ val15 ues, which may seem "unrealistic". The majority of these cases belongs to Nauru, and corresponds to clean atmospheric conditions $\left(\mathrm{AOD}_{500}<0.05\right)$. According to Schuster et al. (2006), positive $\alpha_{1}$ values accompanied by positive curvature can be theoretically derived for very low fine fraction ( 0.3 or even less). Note however that these values in Fig. 12 are associated with large errors and uncertainties in their computations.

According to Schuster et al. (2006), the absolute value of the coefficient $\alpha_{1}$ decreases with increasing particle size for fine monomodal aerosols. Based on this, for negative curvature, as $\alpha_{1}$ tends to zero the particle size should increase. This correlation is more sensitive for monomodal size distributions, while as the coarse fraction increases the correlation is rather neutral, and, therefore, a possible increase in par25 ticle size has no effect on $\alpha_{1}$ values. However, this is not the case when significant coarse-mode aerosols are present and the curvature is positive. Hence, according to our results, for $\alpha_{2}>0$ the coefficient $\alpha_{1}$ decreases with increasing particle size. For a fixed $\alpha_{2}$ value the fine-mode median radius as well as the fine-mode volume fraction increases as the absolute $\alpha_{1}$ values increase.

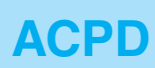

$7,7347-7397,2007$

\section{Aerosol optical properties}

D. G. Kaskaoutis et al.

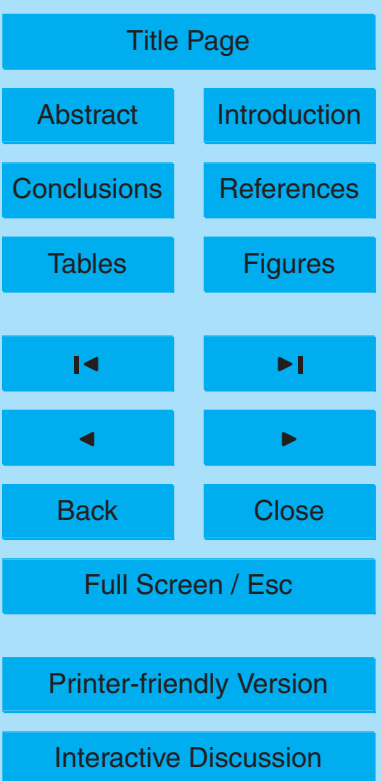

EGU 
According to Schuster et al. (2006) to a first approximation, the Angstrom exponent $\alpha$ can be taken from the difference $\alpha_{2}-\alpha_{1}$. In this section, we attempt to verify the validity of this statement. As already noted in Sects. 4.1 and 4.2, when the curva5 ture is negligible $\left(\alpha_{2} \sim 0\right)$ then $\alpha=-\alpha_{1}$, which is consistent with $\alpha=\alpha_{2}-\alpha_{1}$. Schuster et al. (2006) reported that $\alpha_{2}-\alpha_{1} \geq 2$ corresponds to size distributions dominated by finemode aerosols and $\alpha_{2}-\alpha_{1} \leq 1$ corresponds to size distributions dominated by coarsemode particles, whereas intermediate values of $\alpha_{2}-\alpha_{1}$ correspond to a wide range of fine-mode fractions.

10 In Fig. 13, the differences $\alpha_{2}-\alpha_{1}$ are plotted versus $\mathrm{AOD}_{500}$ for the four AERONET sites. Two dashed lines were included in Fig. 13, i.e. $\alpha_{2}-\alpha_{1}=1$ and $\alpha_{2}-\alpha_{1}=2$, which represent the traditional guidelines for the Ångström exponent. According to our results, values of $\alpha_{2}-\alpha_{1}>2$ are found only in Alta Floresta (8.2\%) and Ispra (21\%), whereas the corresponding values for Nauru and Solar Village do not exceed 1.3 and 1.5, re15 spectively. In contrast, the majority of values for Nauru and Solar Village, i.e. the $96 \%$ and $94.6 \%$, respectively, occur for $\alpha_{2}-\alpha_{1}<1$, indicating the significant coarse-mode fractions in the size distributions of sea-salt and desert-dust particles; The corresponding percentages for Alta Floresta and Ispra are equal to $21.7 \%$ and $15.5 \%$. For clean conditions, i.e. small $\mathrm{AOD}_{500}$, there is a wide range of $\alpha_{2}-\alpha_{1}$ values for all aerosol types. However, for $\mathrm{AOD}_{500}>0.5$, the range of $\alpha_{2}-\alpha_{1}$ values reduces to $0.1-0.5$ for desert-dust, 1.0-1.8 for urban/industrial, and 1.8-2.1 for biomass-burning aerosols. Our results, which are in agreement with those from other investigators (e.g. Cachorro et al., 2001; Holben et al., 2001; Ogunjobi et al., 2004; Reid et al., 1999; Smirnov et al., 2002), indicate that it is possible to achieve a discrimination of aerosols based on correlations between $\alpha_{2}-\alpha_{1}$ and $\mathrm{AOD}_{500}$ values, which is an extension to similar findings based on correlations between Angstrom exponent $\alpha$ and $\mathrm{AOD}_{500}$.

The correlations between the Ångström exponent $\alpha$ and the differences $\alpha_{2}-\alpha_{1}$ are shown in Fig. 14 for the four selected AERONET sites. The $\alpha$ values presented in this

Aerosol optical properties

D. G. Kaskaoutis et al.

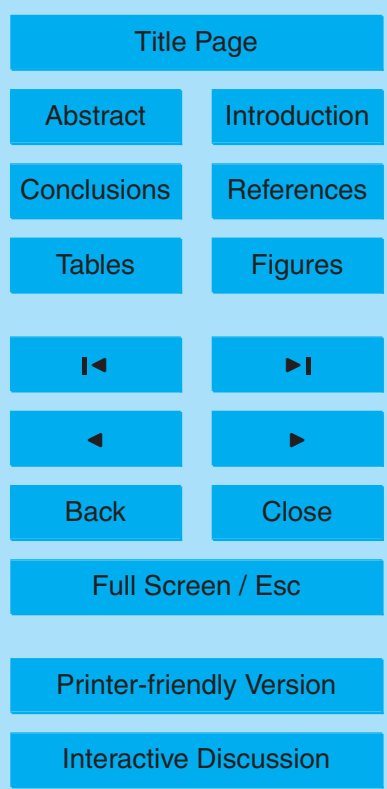

EGU 
figure, were obtained from AERONET in the spectral interval $440-870 \mathrm{~nm}$. Note that the $\alpha_{1}$ and $\alpha_{2}$ values in this graph were obtained from the polynomial fit including the $A O D$ values at 340 and $380 \mathrm{~nm}$. Obviously the two parameters are strongly correlated, as indicated by correlation coefficients ranging from 0.77 to 0.87 . Data points lying 5 onto the one-to-one line or closely around it, indicate the validity of $\alpha_{2}-\alpha_{1}=\alpha$. Our results indicate that only few points are significantly scattered. According to our analysis, these points correspond to cases for which the second-order fit does not provide with high accuracy $\left(R^{2}<0.92\right)$. In Alta Floresta and Ispra, the scatter of data points becomes more significant for $\alpha_{440-870}>1.3$, while in Nauru and Solar Village this occurs 10 for $\alpha_{440-870}<0.8$. Consequently, the assertion $\alpha=\alpha_{2}-\alpha_{1}$ can be considered as valid for intermediate values of $\alpha_{440-870}$. These findings are in agreement with Schuster et al. (2006) reporting that $\alpha=\alpha_{2}-\alpha_{1}$ can be considered as valid for bimodal size distributions with similar contribution from fine-and coarse-mode having $0.8<\alpha<1.3$ (Eck et al., 1999, 2005). In Ispra, the Ångström exponent $\alpha$ mostly overestimates $\alpha_{2}-\alpha_{1}$, while 15 for the other three sites not a systematic overestimation or underestimation is found. The linear regressions for the three representative AERONET sites (Fig. 13) are:

$\alpha_{2}-\alpha_{1}=0.953 \alpha+0.017\left(R^{2}=0.72\right)$ (AltaFloresta)

$\alpha_{2}-\alpha_{1}=0.904 \alpha+0.004\left(R^{2}=0.70\right)$ (Ispra)

$\alpha_{2}-\alpha_{1}=0.819 \alpha+0.106\left(R^{2}=0.78\right)($ Nauru $)$

20

$\alpha_{2}-\alpha_{1}=0.804 \alpha+0.058\left(R^{2}=0.75\right) \quad($ SolarVillage)

Note that these linear regressions have larger coefficients $R^{2}$ than the regressions shown in Fig. 10, for all aerosol types. This underlines that the curvature plays an important role in the spectral variation of AOD and $\alpha$ and, therefore, should always be considered.

Aerosol optical properties

D. G. Kaskaoutis et al.

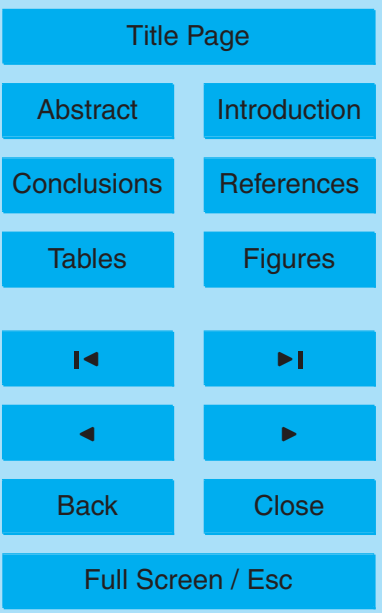

Printer-friendly Version

Interactive Discussion 
In this section, the computed $\alpha_{340-870}$ values are compared with those obtained by AERONET http://aeronet.gsfc.nasa.gov/. In addition, an extensive analysis is performed on the errors in the computations of $\alpha$ depending on turbidity.

5 The regressions between the computed values $\alpha_{340-870}$ and those of AERONET $\left(\alpha_{440-870}\right)$ are given in Fig. 15 for the four representative AERONET sites. The mean and standard deviation values of $\alpha$ together with statistics are given for each site. In general, the two Angstrom parameters are highly correlated, and only in few cases significant differences exist. Most of these differences appear in Nauru, where the computed $\alpha$ values systematically overestimate the respective AERONET ones, in contrast to the three other sites, where the agreement is better. The equations of the linear regression fits are:

$$
\begin{aligned}
\alpha_{340-870} & =0.86(0.01) \alpha_{440-870}+0.15(0.02) R^{2}=0.89 \text { (AltaFloresta) } \\
\alpha_{340-870} & =0.89(0.01) \alpha_{440-870}+0.04(0.02) R^{2}=0.90 \text { (Ispra) } \\
15 \quad \alpha_{340-870} & =1.03(0.02) \alpha_{440-870}+0.17(0.01) R^{2}=0.81 \text { (Nauru) } \\
\alpha_{340-870} & =0.99(0.01) \alpha_{440-870}+0.04(0.004) R^{2}=0.96 \text { (SolarVillage) }
\end{aligned}
$$

Our analysis has shown that the overestimation of $\alpha_{340-870}$ values in Nauru are mainly attributed to large AOD values at $340 \mathrm{~nm}$ and $380 \mathrm{~nm}$, which are also responsible for the large $\alpha_{380-440}$ values shown in Fig. 2 . The larger or smaller computed $\alpha_{340-870}$ than AERONET $\alpha_{440-870}$ values are related to the shape of the curvature of the InAOD versus $\ln \lambda$, or in other words to the value of its second derivative. Therefore, in cases where the curve is concave $\left(\alpha_{2}>0\right.$ or $\left.<0\right)$ the rate of change of $\alpha$ decreases with increasing wavelength, so that including AODs at shorter wavelengths (e.g. 340 and $380 \mathrm{~nm}$ ) may result in an increase of $\alpha_{340-870}$. This is obvious in Nauru and Solar

Aerosol optical properties

D. G. Kaskaoutis et al.

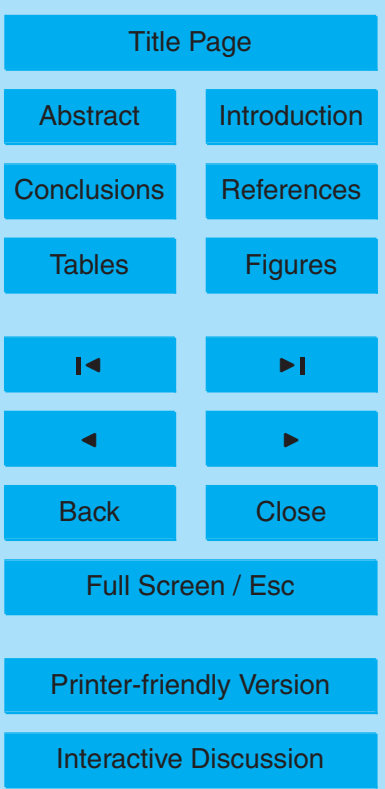


desert-dust particles present concave-type curves (Eck et al., 1999). The opposite occurs in Ispra and Alta Floresta (negative biases $\alpha_{340-870}-\alpha_{440-870}$ ). However, it is noticeable that in Alta Floresta, for small values of $\alpha$ (i.e. for high concentration of coarse-mode particles) the computed $\alpha_{340-870}$ values are higher than the AERONET, 5 while for $\alpha>1.5$ the AERONET $\alpha$ values are higher.

The errors in computations of $\alpha_{340-870}$ using the least-squares method as a function of turbidity conditions are shown in Fig. 16. These errors are attributed to the curvature, which consists a measure of the departure from the linear relationship. For each station the mean error with the standard deviation are also given. The larger errors 10 are produced for Nauru $(0.15 \pm 0.07)$ and smallest ones for Solar Village $(0.04 \pm 0.09)$. It is thus expected that the smallest errors occur in Solar Village, since this site has the smallest $\alpha_{2}$ values, and the smallest differences between the computed values of $\alpha$ in different spectral bands (see Figs. 2 and 15). Figure 16 reveals that the errors in computations decrease with increasing $A \mathrm{D}_{500}$. This is more evident in Nauru and 15 Solar Village. This is explained by the fact that under clear conditions, the scatter in the AOD values is larger, and the Ångström formula does not fit well (Pedrós et al., 2003; Kaskaoutis et al., 2006). Therefore, to avoid such errors and uncertainties, the aerosol computations based on data from the AERONET database should be limited only under high-turbidity conditions, as also stated by other investigators (Dubovik et al., 2000; Eck et al., 2005; Smirnov et al. 2002).

\section{Conclusions}

The wavelength dependence of Ångström exponent, $\alpha$, which causes a curvature in the relationship between the logarithm of the spectral aerosol optical depth, InAOD, and that of wavelength, $\ln \lambda$, was investigated in this study. The study was performed using data from four AERONET sites, which are representative of different aerosol types, namely biomass burning, urban/industrial, maritime and desert dust. The data obtained from AERONET consisted in AOD at 6 wavelengths, 340, 380, 440, 500, 675

\section{ACPD}

$7,7347-7397,2007$

Aerosol optical properties

D. G. Kaskaoutis et al.

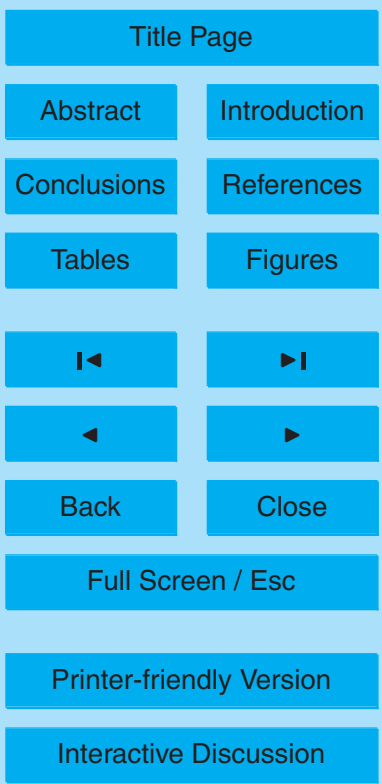


and $870 \mathrm{~nm}$, and values of $\alpha$ in the spectral interval $440-870 \mathrm{~nm}$. In addition, values of $\alpha$ were computed for each site in the $340-870 \mathrm{~nm}$ spectral interval using the leastsquares method. Subsequently, linear and second-order polynomial fits were applied to the InAOD versus $\ln \lambda$ values. The main conclusions can be summarized as follows:

- Large differences were encountered between the $\alpha$ values computed in two different narrow spectral bands, 380-440 and $675-870 \mathrm{~nm}$, for the all aerosol types indicating a significant wavelength dependence of $\alpha$. These differences, which are related to the curvature $\alpha_{2}$, are especially large for low turbidity conditions whereas they decrease with increasing AOD.

10 - The values of $\alpha$ computed at shorter wavelengths $\left(\alpha_{380-440}\right)$ are larger than those at longer wavelengths $\left(\alpha_{675-870}\right)$ in case of positive curvature $\left(\alpha_{2}>0\right)$ or equivalently in case of negative second derivative of the Angstrom exponent $(<0)$ implying concavetype curves, which are characteristic of aerosol size distributions with a significant fraction of coarse-mode. The opposite, i.e. $\alpha_{380-440}<\alpha_{675-870}$, exists for convex type 5 curves, being characteristic of aerosol size distributions dominated by fine-mode. However, the spectral differences in $\alpha$ values, $\alpha_{380-440}-\alpha_{675-870}$, are significantly correlated with the curvature $\alpha_{2}$ only when the latter is computed through a the polynomial fit applied in the same spectral interval with that covered by $\alpha_{380-440}$ and $\alpha_{675-870}$, i.e. from 380 to $870 \mathrm{~nm}$.

- The correlations between the coefficients $\alpha_{1}$ and $\alpha_{2}$ of the applied 2nd-order polynomial fits, and the values $\mathrm{AOD}_{500}$, exhibit significant scatter for the four examined aerosol types. Values of $\alpha_{2}$ close to zero (range \pm 0.01 ), implying no curvature, were found only in very few cases $(2 \%-2.5 \%)$. For turbid conditions, i.e. large $\mathrm{AOD}_{500}$ values, in Alta Floresta and Ispra, the $\alpha_{2}$ values are negative indicating the strong presence of fine-mode particles (smoke or pollution, respectively) implying a strong curvature effect. In contrast, under high turbidities in Solar Village, the spectral variation of $\alpha$ is smaller.

- It is difficult to identify specific aerosol types based solely on Angstrom exponent

\section{Aerosol optical properties}

D. G. Kaskaoutis et al.

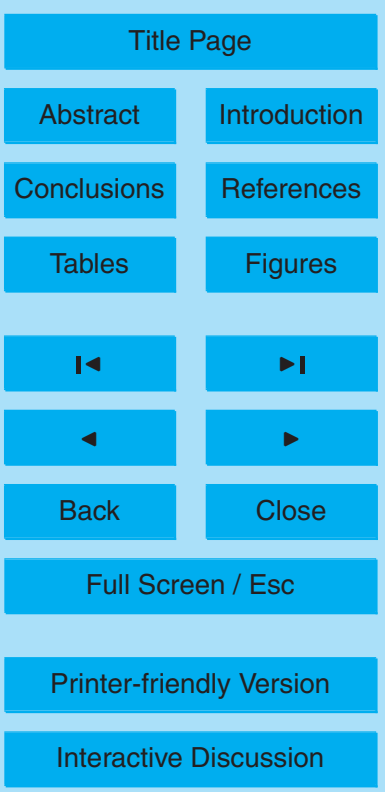


$\alpha$ values since a wide range of $\alpha_{2}$ values exists for a specific value of $\alpha$ for the four examined aerosol types. On the contrary, a better discrimination can be achieved by using combined information of the coefficients $\alpha_{1}$ and $\alpha_{2}$ (curvature). Nonetheless, the values of $\alpha$ were found to be significantly correlated with the differences $\alpha_{1}-\alpha_{2}$.

- The common diagrams correlating values of $\alpha_{1}, \alpha_{2}$ with those of $\alpha$ can be effectively used for discriminating between the four different aerosol types. Especially, the curvature can be a useful tool to this aim at intermediate values of $\alpha$. Furthermore, important information on aerosol types can be obtained through correlations between the coefficients $\alpha_{1}$ and $\alpha_{2}$.

- The estimated $\alpha$ values using the least-squares method in the spectral band 340$870 \mathrm{~nm}$ were found to be significantly correlated with the AERONET Angstrom exponent $\alpha$ values (correlation coefficients ranging from 0.81 to 0.96 ). Therefore, the values of $\alpha$ should be determined in wide spectral intervals for better accuracy.

- However, the errors in computations of Angstrom exponent significantly increase under low turbid conditions. Under such conditions, the spectral variation of $\alpha$ can be significant and therefore, the use of a polynomial fit is needed, since the simple Ångström formula is not appropriate for describing the spectral dependence of AOD.

20 Acknowledgements. We thank B. Holben for his effort in establishing and maintaining the Aeronet Alta Floresta site, G. Zibordi for his effort in establishing and maintaining the Aeronet Ispra site, $\mathrm{R}$. Wagener for his effort in establishing and maintaining the Aeronet Nauru site and N. Al-Abbadi for his effort in establishing and maintaining the Aeronet Solar Village site.

\section{References}

25 Ångström, A. K.: On the atmospheric transmission of sun radiation and on the dust in the air, Geogr. ANN., 12, 130-159, 1929.

Aerosol optical properties

D. G. Kaskaoutis et al.

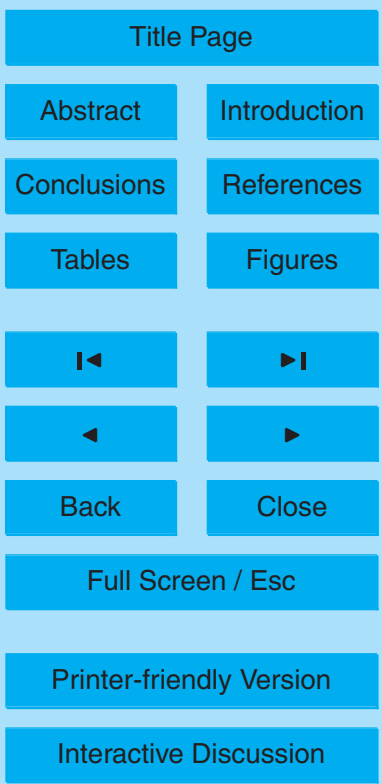


Artaxo, P., Gerab, F., Yamasoe, M. A., and Martins, J. V.: Fine mode aerosol composition at three long-term atmospheric monitoring sites in the Amazon Basin, J. Geophys. Res., 99, 22 857-22 868, 1994.

Cachorro, V. E. and de Frutos, A. M.: A revised study of the validity of the general Junge relationship at solar wavelengths: Application to vertical atmospheric aerosol layer studies, Atmos. Res., 39, 113-126, 1995.

Cachorro, V. E., Vergaz, R., and de Frutos, A. M.: A quantitative comparison of $\alpha$ Ångström turbidity parameter retrieved in different spectral ranges based on spectroradiometer solar radiation measurements, Atmos. Envir., 35, 5117-5124, 2001.

Dellago, $\mathrm{C}$. and Horvath, $\mathrm{H}$.: On the accuracy of the size distribution information obtained from light extinction and scattering measurements, I, Basic considerations and models, J. Aeros. Sci., 24, 129-141, 1993.

Dubovik, O., Smirnov, A., Holben, B. N, King, M. D., Kaufman, Y. J., Eck, T. F., and Slutsker, I.: Accuracy assessments of aerosol properties retrieved from Aerosol Robotic Network (AERONET) sun and sky radiance measurements, J. Geophys. Res., 105, 9791-9806, 2000.

Dubovik, O., Holben, B. N, Eck, T. F., Smirnov, A., Kaufman, Y. J., King, M. D., Tanrè, D., and Slutsker, I.: Variability of absorption and optical properties of key aerosol types observed in worldwide locations, J. Atmos. Sci., 59, 590-608, 2002.

20 Eck, T. F., Holben, B. N., Reid, J. S., Dubovic, O., Smirnov, A., O'Neil, N. T., Slutsker, I., and Kinne, S.: Wavelength dependence of the optical depth of biomass burning, urban, and desert dust aerosols, J. Geophys. Res., 104(D24), 31 333-31 349, 1999.

Eck, T. F., Holben, B. N., Dubovic, O., Smirnov, A., Slutsker, I., Lobert, J. M., and Ramanathan, V.: Column-integrated aerosol optical properties over the Maldives during the northeast monsoon for 1998-2000, J. Geophys. Res., 106, 28 555-28566, 2001a.

Eck, T. F., Holben, B. N., Ward, D. E., Dubovic, O., Reid, J. S., Smirnov, A., Mukelabai, M. M., Hsu, N. C., O' Neil, N. T., and Slutsker, I.: Characterization of the optical properties of biomass burning aerosols in Zambia during the 1997 ZIBBEE field campaign, J. Geophys. Res., 106(D4), 3425-3448, 2001b.

30 Eck, T. F., Holben, B. N., Ward, D. E., et al.: Variability of biomass burning aerosol optical characteristics in southern Africa during SAFARI 2000 dry season campaign and a comparison of single scattering albedo estimates from radiometric measurements, J. Geophys. Res., 108(D13), 8477, doi:10.1029/2002JD002321, 2003.

\section{Aerosol optical properties}

D. G. Kaskaoutis et al.

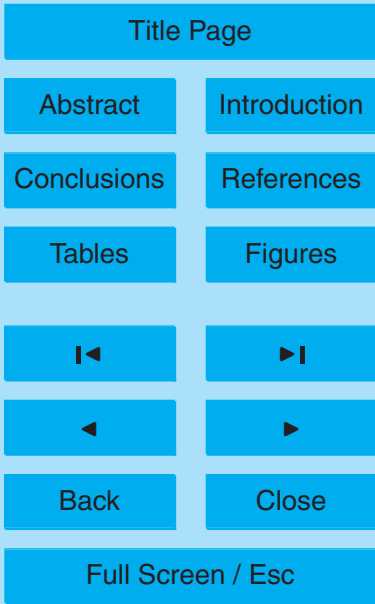

Printer-friendly Version

Interactive Discussion 
Eck, T. F., Holben, B. N., Dubovic, O., Smirnov, A., Goloub, P., Chen, H. B., Chatenet, B., Gomes, L., Zhang, X. Y., Tsay, S. C., Ji, Q., Giles, D., and Slutsker, I.: Columnar aerosol optical properties at AERONET sites in central eastern Asia and aerosol transport to the tropical mid-Pacific, J. Geophys. Res., 110, D06202, doi:10.1029/2004JD005274, 2005.

5 Granger Morgan, M., Adams, P. J., and Keith, D. W.: Elicitation of expert judgments of aerosol forcing, Clim. Change, 75, 195-214, 2006.

Hansen, J., Sato, M., Ruedy, R., Lacis, A., and Oinas, V.: Global warming in the twenty-first century: An alternative scenario, Proc. Natl. Acad. Sci., USA, 97, 9875-9880, 2000.

Holben, B. N., Tanre, D., Smirnov, A., Eck, T. F., Slutsker, I., et al.: An emerging ground-based aerosol climatology: Aerosol optical depth from AERONET, J. Geophys. Res., 106, 12 06712097, 2001.

Houghton, J. T., Miera Filho, L. G., Callander, B. A., Harris, N., Kattenberg, A., and Maskell, K.: Climate Change 1995: The Science of Climate Change: Intergovernmental Panel on Climate Change, Cambridge Univ. Press, p 552, 1996.

15 Junge, C. E.: The size distribution and aging of natural aerosols as determined from electrical and optical measurements in the atmosphere, J. Meteorol., 12, 13-25. 1955.

Kaskaoutis, D. G. and Kambezidis, H. D.: Investigation on the wavelength dependence of the aerosol optical depth in the Athens area, Q. J. R. Meteorol. Soc., 132, 2217-2234, 2006.

Kaskaoutis, D. G., Kambezidis, H. D., Adamopoulos, A. D., and Kassomenos, P. A.: Comparison between experimental data and modeling estimates of atmospheric optical depth over Athens, Greece, J. Atmos. Solar Terr. Phys., 68, 1167-1178, 2006.

Kaskaoutis, D. G., Kambezidis, H. D., Hatzianastassiou, N., Kosmopoulos, P. G., and Badarinath, K. V. S.: Aerosol climatology: On the discrimination of aerosol types over four AERONET sites, Atmos. Chem. Phys. Discuss., accepted, 2007.

Kaufman, Y. J., Gitelson, A., Karnieli, A., Ganor, E., Fraser, R. S., Nakajima, T., Matoo, S., and Holben, B. N.: Size distribution and scattering phase function of aerosol particles retrieved from sky brightness measurements, Geophys. Res. Let., 99, 10341-10 356, 1994.

Kaufman, Y. J., Tanrè, D., Remer, L. A., Vermote, E. F., Chu, A., and Holben, B. N.: Operational remote sensing of tropospheric aerosol over land from EOS moderate resolution imaging spectroradiometer, J. Geophys. Res., 102, 17 051-17 067, 1997.

Keil, A. and Haywood, J. M.: Solar radiative forcing by biomass burning aerosol particles during SAFARI 2000: A case study based on measured aerosol and cloud properties, J.Geophys. Res., 108(D13), 8467, doi:10.1029/2002JD002315, 2003.

Aerosol optical properties

D. G. Kaskaoutis et al.

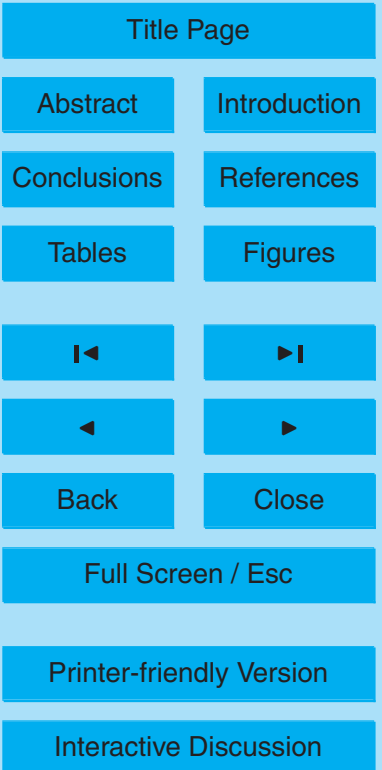


King, M. D. and Byrne, D. M.: A method for inferring total ozone content from spectral variation of total optical depth obtained with a solar radiometer, J. Atmos. Sci., 33, 2242-2251, 1976.

King, M. D., Kaufman, Y. J., Tanre, D., and Nakajima, T.: Remote sensing of tropospheric aerosols from space: Past, present, and future, Bull. Am. Meteorol. Soc., 80, 2229-2259, 1999.

Ogunjobi, K. O., He, Z., Kim, K. W., and Kim, Y. J.: Aerosol optical depth during episodes of Asian dust storms and biomass burning at Kwangju, South Korea, Atmos. Environ., 38, 1313-1323, 2004.

O'Neill, N. and Royer, A.: Extraction of bimodal aerosol size distribution radii from spectral and angular slope Ångström coefficients, Appl. Opt., 32, 1642-1645, 1993.

O'Neill, N. T., Dubovic, O., and Eck, T. F.: Modified Ångström exponent for the characterization of submicrometer aerosols, Appl. Opt., 40(15), 2368-2375, 2001 a.

O'Neill, N. T., Eck, T. F., Holben, B. N., Smirnov, A., and Dubovic, O.: Bimodal size distribution influences on the variation of Angström derivates in spectral and optical depth space, J.

15 Geophys. Res., 106(D9), 9787-9806, 2001b.

O'Neill, N. T., Eck, T. F., Smirnov, A., Holben, B. N., and Thulasiraman, S.: Spectral discrimination of coarse and fine mode optical depth, J. Geophys. Res., 198(D17), 4559, doi:101029/2002JD002975, 2003.

Pedrós, R., Martinez-Lozano, J. A., Utrillas, M. P., Gómez-Amo, J. L., and Tena, F.: Columnintegrated aerosol, optical properties from ground-based spectroradiometer measurements at Barrax (Spain) during the Digital Airborne Imaging Spectrometer Experiment (DAISEX) campaigns, J. Geophys. Res., 108(D18), 4571, doi:10.1029/2002JD003331, 2003.

Reid, J. S., Eck, T. F., Christopher, S. A., Hobbs, P. V., and Holben, B. N.: Use of the Ångström exponent to estimate the variability of optical and physical properties of aging smoke particles in Brazil, J. Geophys. Res., 104(D22), 27 473-27 489, 1999.

Remer, L. A. and Kaufman, Y. J.: Aerosol direct radiative effect at the top of the atmosphere over cloud free ocean derived from four years of MODIS data, Atmos. Chem. Phys., 6, 237253, 2006,

http://www.atmos-chem-phys.net/6/237/2006/.

so Remer, L. A., Kaufman, Y., Holben, B. N., Thompson, A. M., and McNamara, D. P.: Biomass burning aerosol size distribution and modeled optical properties, J. Geophys. Res., 103, 31 879-31 891, 1998.

Schuster, G. L., Dubovik, O., and Holben, B. N.: Ångström exponent and bimodal aerosol size

Aerosol optical properties

D. G. Kaskaoutis et al.

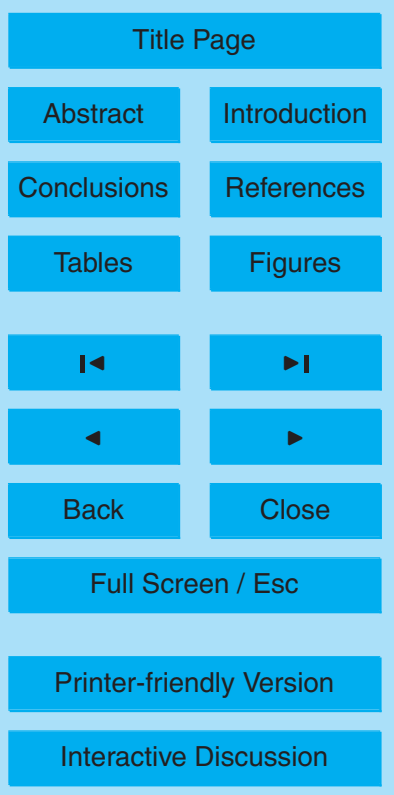

EGU 
distributions, J. Geophys. Res., 111, D07207, doi:101029/2005JD006328, 2006.

Shifrin, K. S.: Simple relationships for the ?ngström parameter of disperse systems, Appl. Opt., 34, 4480-4485, 1995.

Smirnov, A., Holben, B. N., Eck, T. F., Dubovik, O., and Slutsker, I.: Cloud screening and quality control algorithms for the AERONET data base, Remote Sens. Environ., 73, 337-349. 2000.

Smirnov, A., Holben, B. N., Kaufman, Y. J., Dubovic, O., Eck, T. F., Slutsker, I., Pietras, C., and Halthore, R. N.: Optical properties of atmospheric aerosol in Maritime Environments, J Atmos. Sci., 59, 501-523, 2002.

Smirnov, A., Holben, B. N., Dubovic, O., Fruin, R., Eck, T. F., and Slutsker, I.: Maritime component in aerosol optical models derived from aerosol robotic network data, J. Geophys. Res., 108(D1), 4033, doi:10.1029/2002JD002701, 2003.

Tomasi, C., Caroli, E., and Vitale, V.: Study of the relationship between Ångström's wavelength exponent and Junge particle size distribution exponent, J. Clim. Appl. Meteorol., 22, 17071716, 1983.

Yu, H., Kaufman, Y. J., Chin, M., Feingold, G., Remer, L. A., Anderson, T. L., Balkanski, Y., Bellouin, N., Boucher, O., Christopher, S., DeCola, P., Kahn, R., Koch, D., Loeb, N., Reddy, M. S., Schulz, M., Takemura, T. and Zhou, M.: A review of measurement-based assessment of aerosol direct radiative effect and forcing, Atmos. Chem. Phys., 6, 613-666, 2006, http://www.atmos-chem-phys.net/6/613/2006/.

Zhao, T. X.-P., Laszlo, I., Minnis, P., and Remer, L.: Comparison and analysis of two aerosol retrievals over the ocean in the Terra/Clouds and the Earth's Radiant Energy System-Moderate Resolution Imaging Spectroradiometer single scanner footprint data: 1. Global evaluation, J. Geophys. Res., 110, D21208, doi:10.1029/2005JD005851, 2005.

Aerosol optical properties

D. G. Kaskaoutis et al.

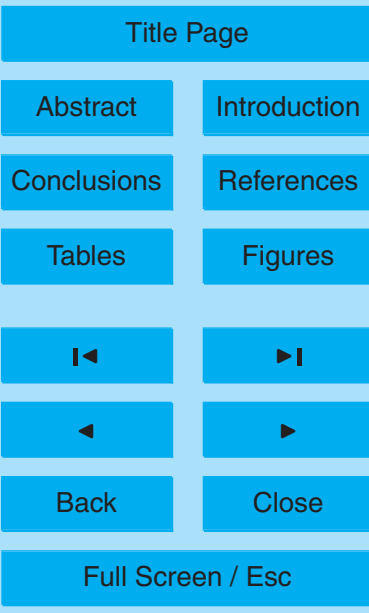

Printer-friendly Version

Interactive Discussion 


\section{ACPD}

$7,7347-7397,2007$

Aerosol optical properties

Table 1. Period of measurements of aerosol optical properties at four selected AERONET stations and number of daily mean data in each site per season. In parentheses they are also given the percentages of the total number of measurements to which correspond the seasonal data.

\begin{tabular}{|c|c|c|c|c|c|c|}
\hline Location & $\begin{array}{l}\text { Period of } \\
\text { measurements }\end{array}$ & Total & Winter & Spring & Summer & Autumn \\
\hline Alta Floresta & Jan/02-Dec/04 & 561 & $90(16.0 \%)$ & $124(22 \%)$ & $181(32 \%)$ & $166(30 \%)$ \\
\hline Ispra & Jan/02-Mar/04 & 653 & $148(23 \%)$ & 165 (25\%) & 217 (33\%) & $123(19 \%$ \\
\hline Nauru & Mar/02-May/04 & 363 & $78(21 \%)$ & $131(36 \%)$ & $79(22 \%)$ & $75(21 \%)$ \\
\hline Solar Village & Jan/02-Aug/04 & 792 & $169(21 \%)$ & 242 (31\%) & $209(26 \%)$ & $172(22 \%)$ \\
\hline
\end{tabular}

D. G. Kaskaoutis et al.

Title Page

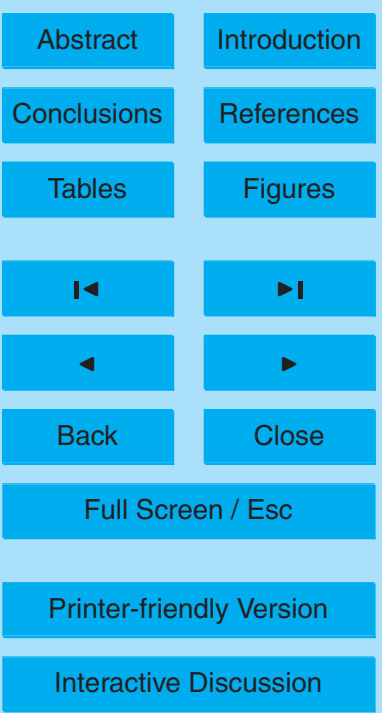




\section{ACPD}

7, 7347-7397, 2007

\section{Aerosol optical properties}

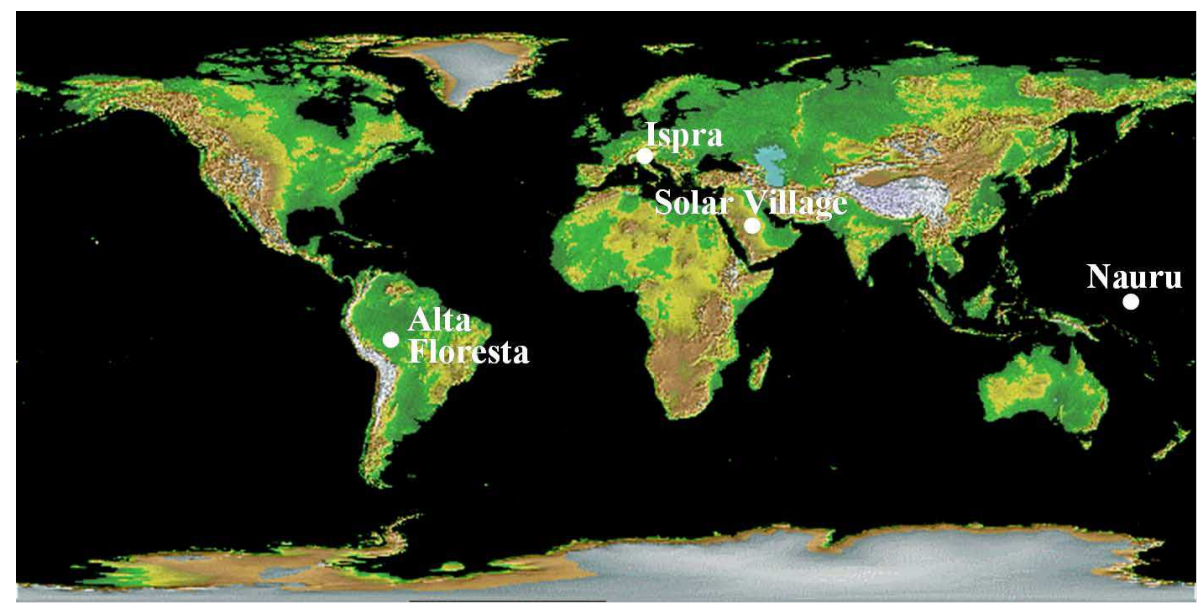

D. G. Kaskaoutis et al.

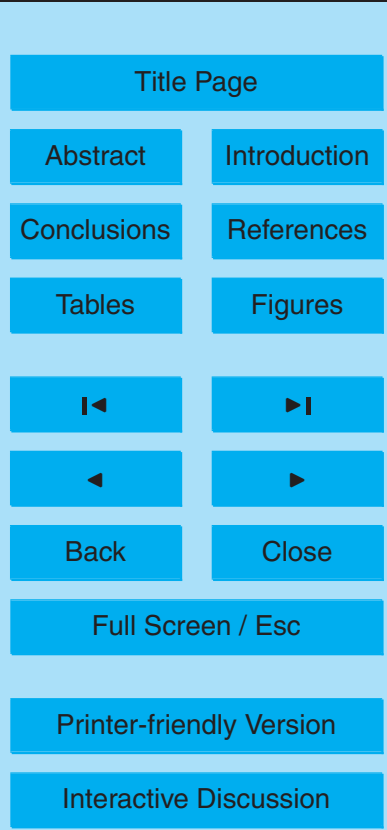

Fig. 1. Global map of the four selected AERONET sites. 


\section{ACPD}

\section{$7,7347-7397,2007$}
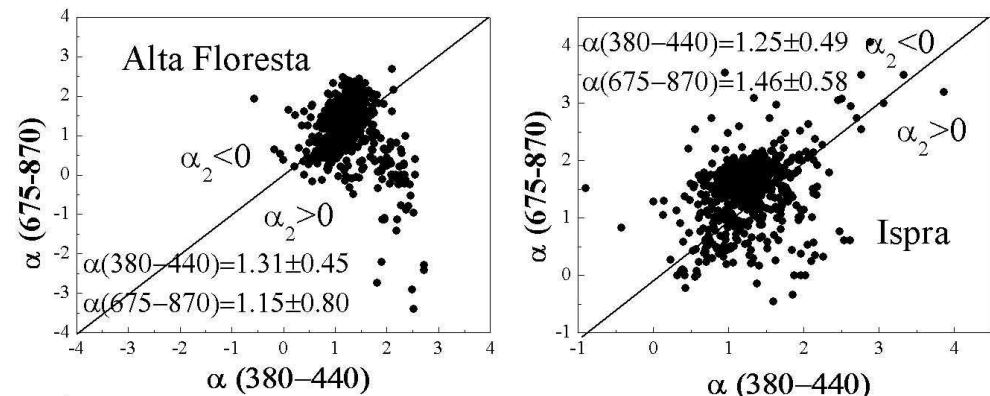

\section{Aerosol optical properties}

\section{G. Kaskaoutis et al.}
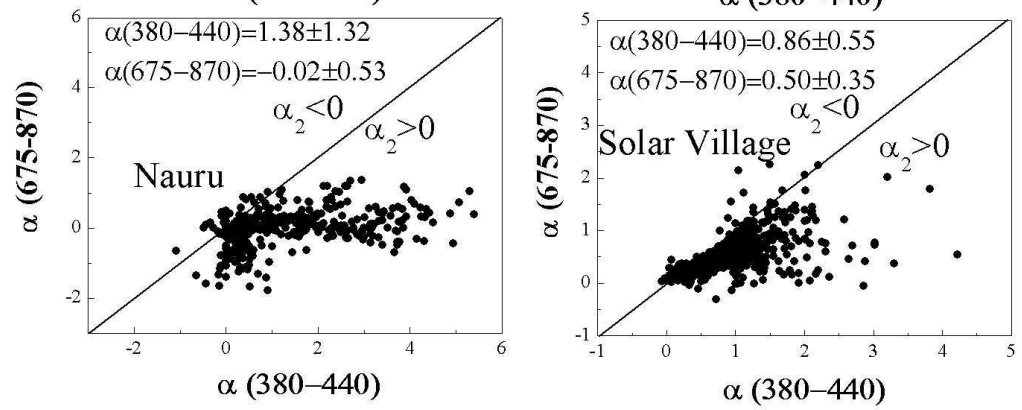

Title Page

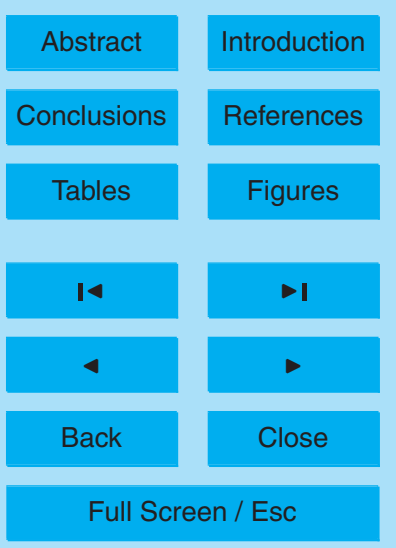

Fig. 2. Regression between the values of Ångström wavelength exponent $\alpha$ computed at shorter $(380-440 \mathrm{~nm})$ and longer $(675-870 \mathrm{~nm})$ wavelengths for the four representative AERONET sites: (a) Alta Floresta, (b) Ispra, (c) Nauru, and (d) Solar Village. The one-toone line is also shown together with $\alpha_{2}$ values implying positive (concave type) or negative (convex type) curves related to Eq. (5). 

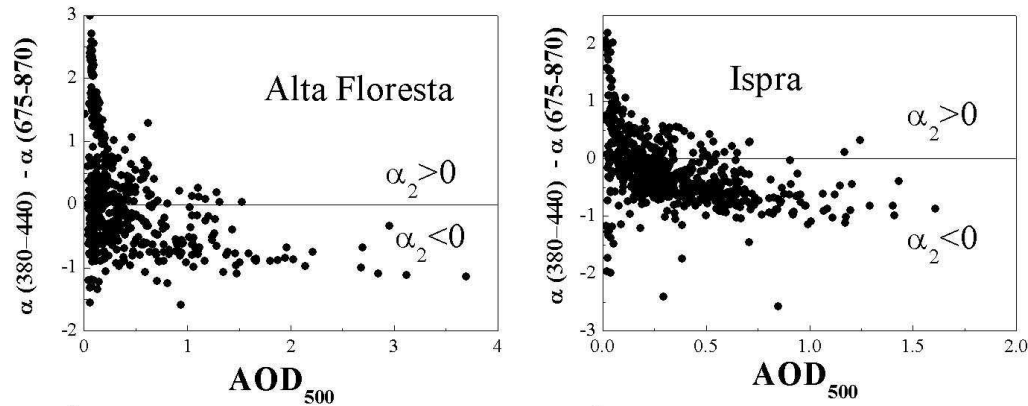

\section{ACPD}

\section{7, 7347-7397, 2007}

\section{Aerosol optical properties}

D. G. Kaskaoutis et al.
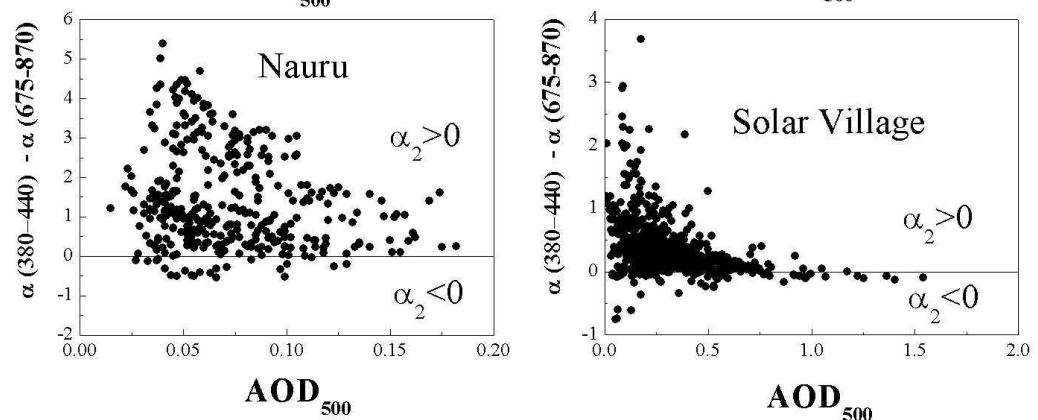

Title Page

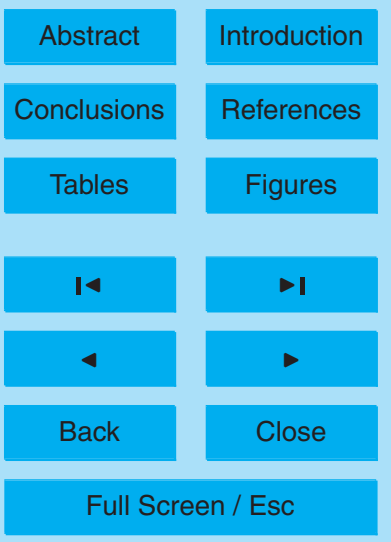

Fig. 3. Correlation between the differences of Ångström exponent, $\alpha_{380-440}-\alpha_{675-870}$, and $\mathrm{AOD}_{500}$. 
(a)
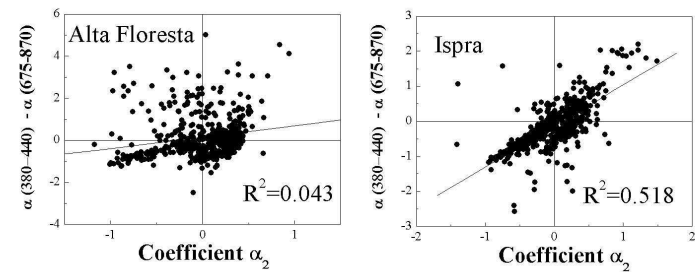

\section{ACPD}

$7,7347-7397,2007$

\section{Aerosol optical properties}

D. G. Kaskaoutis et al.
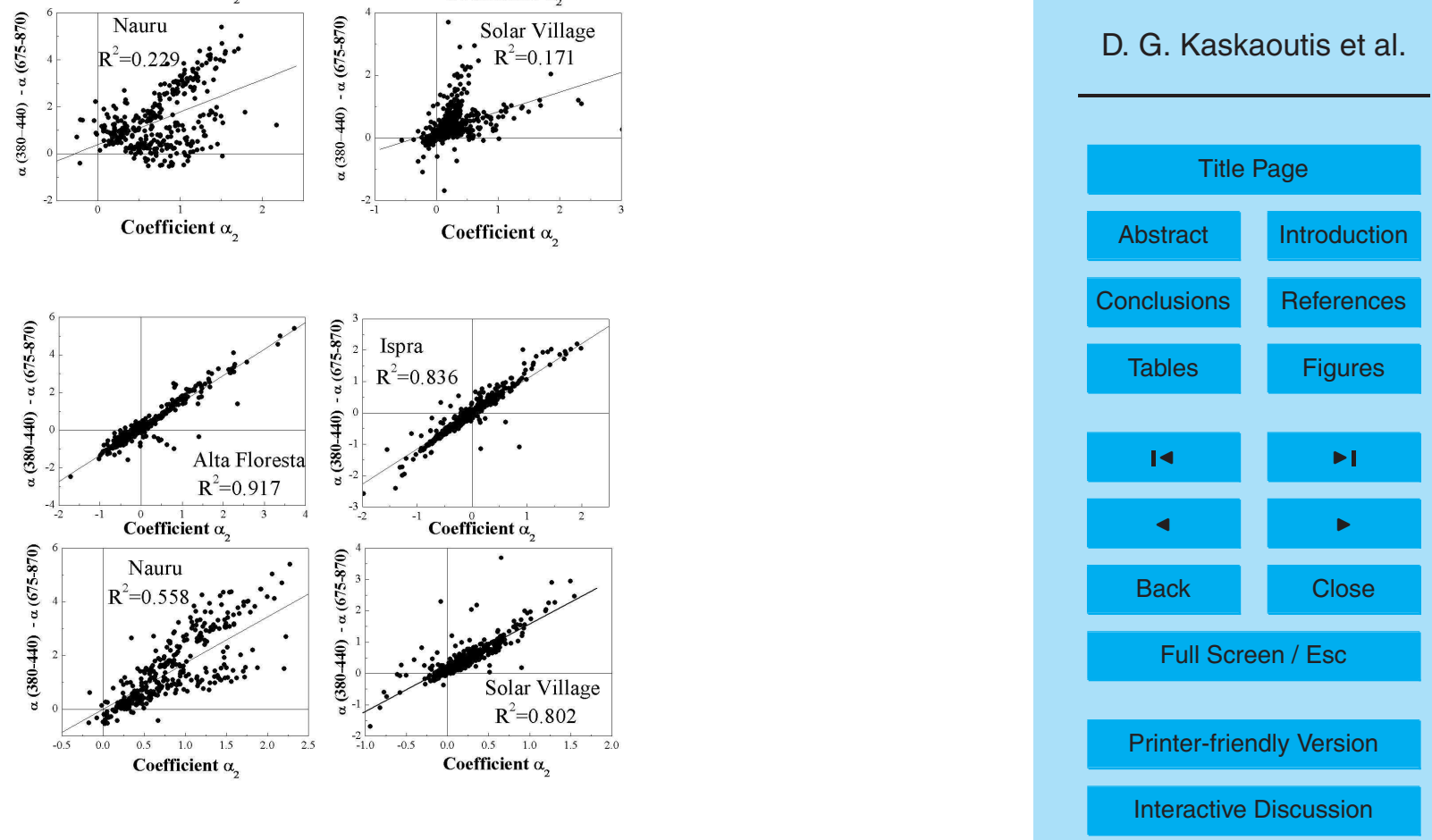

Fig. 4. Correlation between the differences $\alpha_{380-440}-\alpha_{675-870}$ and the values of coefficient $\alpha_{2}$ (see Eq. 5) (a) in the 340-870 nm spectral interval, and (b) in the 380-870 nm spectral interval. 


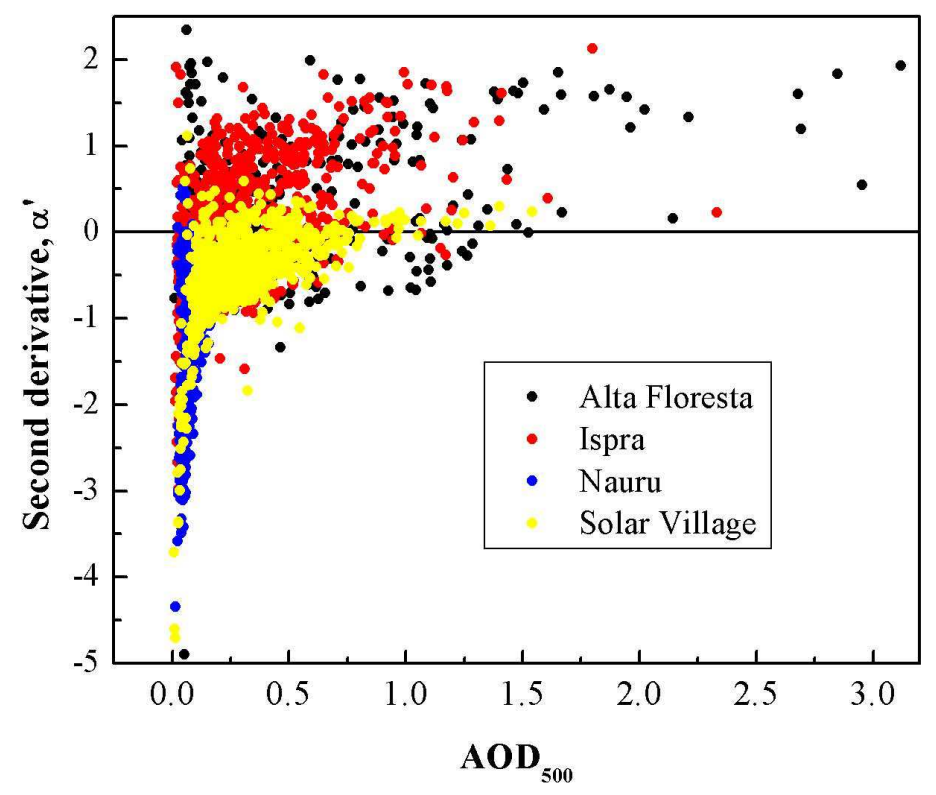

Fig. 5. Values of (d $\alpha / \mathrm{d} \ln \lambda$, Eq. 6) computed from instantaneous AOD values at $340,380,440$, 500,657 and $870 \mathrm{~nm}$ as a function of AOD at $500 \mathrm{~nm}$ for the four representative AERONET sites.
ACPD

$7,7347-7397,2007$

Aerosol optical properties

D. G. Kaskaoutis et al.

Title Page

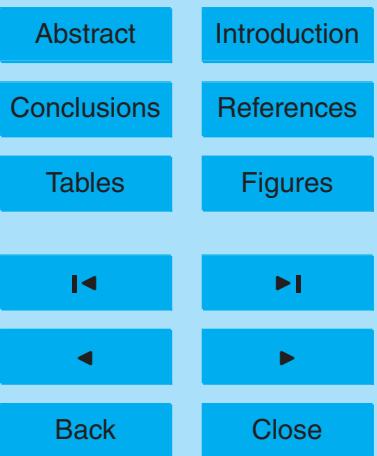

Full Screen / Esc

Printer-friendly Version

Interactive Discussion 


\section{ACPD}

$7,7347-7397,2007$
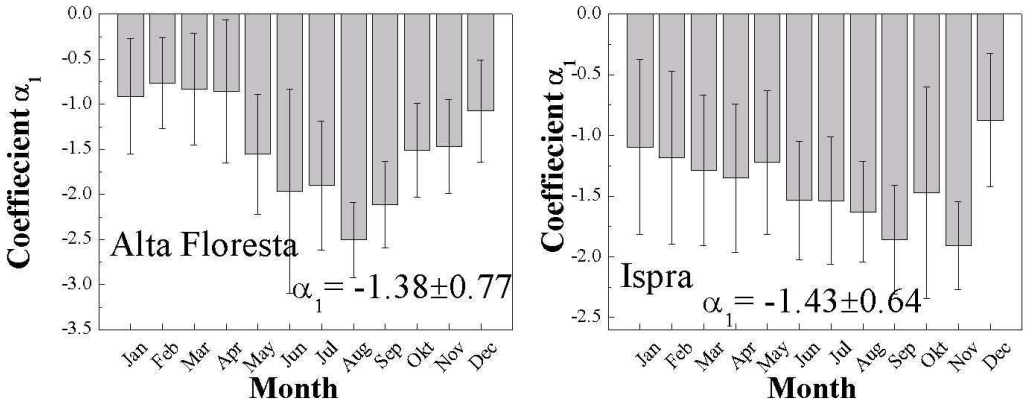

\section{Aerosol optical properties}

D. G. Kaskaoutis et al.
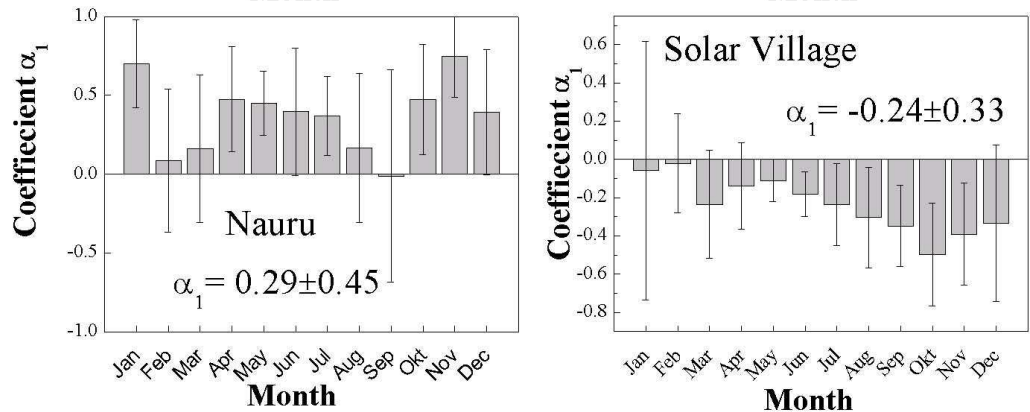

Title Page

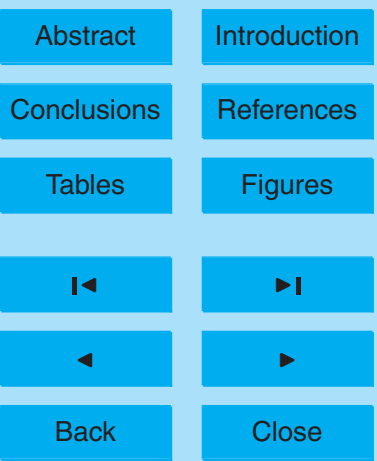

Full Screen / Esc

Fig. 6. Seasonal variation of $\alpha_{1}$ at the four representative AERONET sites computed from the polynomial fit in the spectral interval $340-870 \mathrm{~nm}$. The vertical bars correspond to the associated standard deviations.

Printer-friendly Version

Interactive Discussion 


\section{ACPD}

7, 7347-7397, 2007
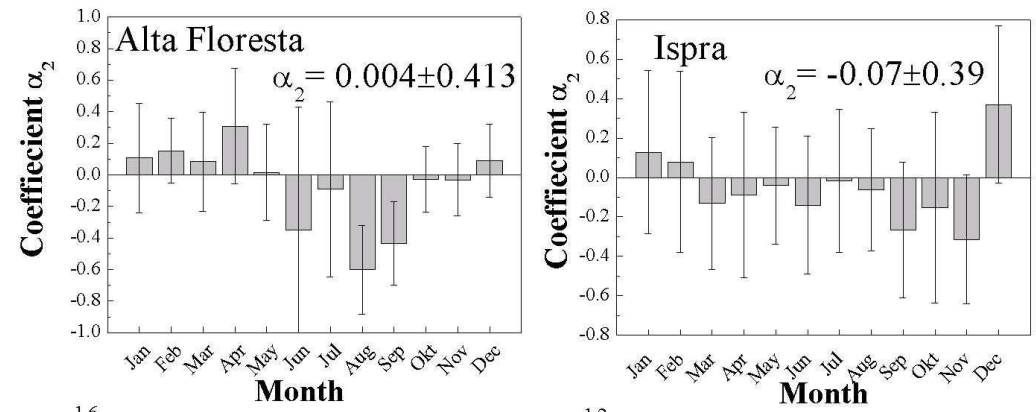

\section{Aerosol optical properties}

D. G. Kaskaoutis et al.
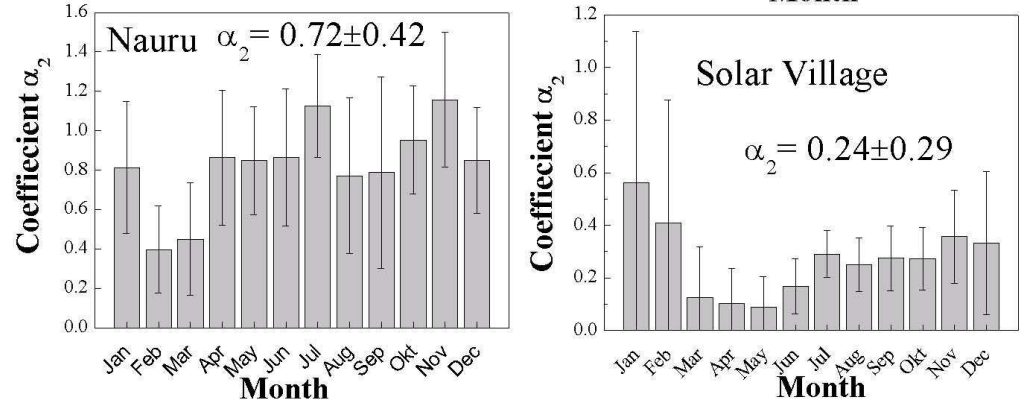

Title Page

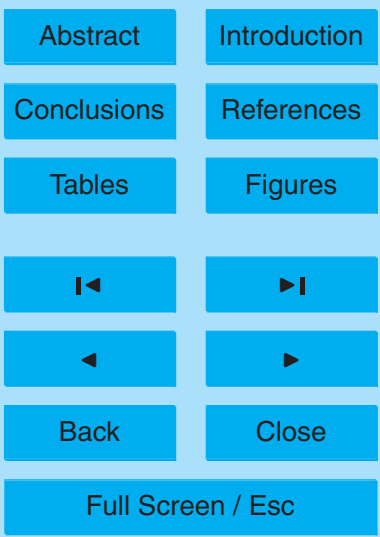

Fig. 7. As in Fig. 6, but for the coefficient $\alpha_{2}$. 


\section{ACPD}

\section{$7,7347-7397,2007$}
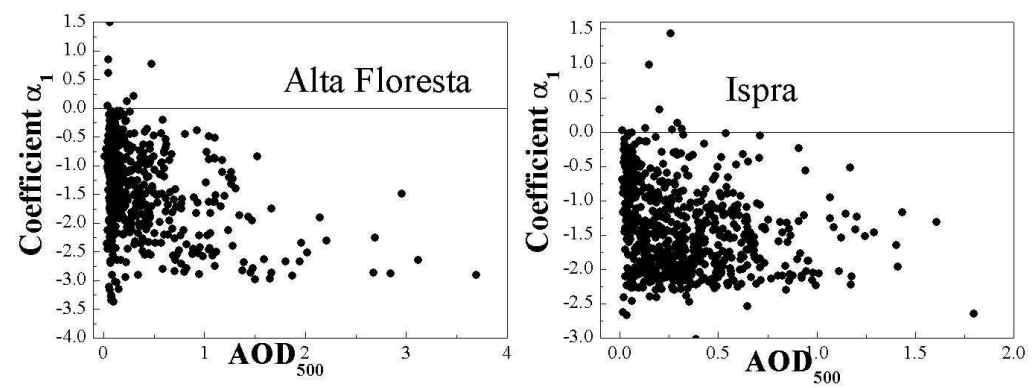

\section{Aerosol optical properties}

\section{G. Kaskaoutis et al.}
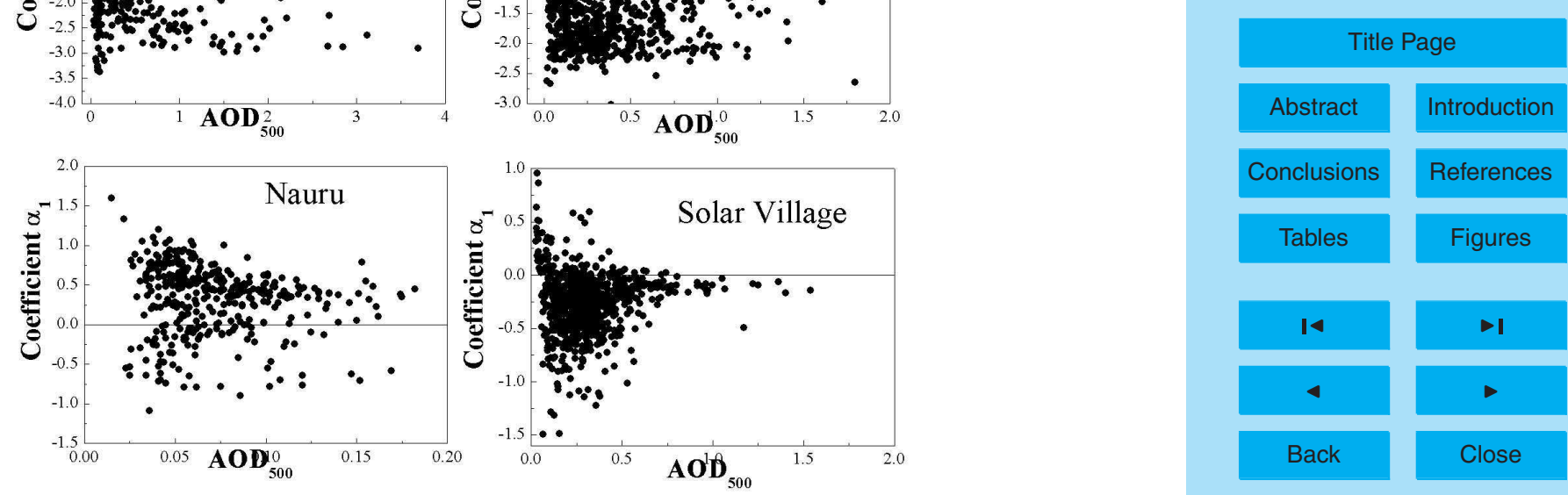

Full Screen / Esc

Fig. 8. Correlation between the coefficient $\alpha_{1}$ computed in the spectral interval $340-870 \mathrm{~nm}$ and $A O D_{500}$ for the four representative AERONET sites. 


\section{ACPD}

7, 7347-7397, 2007
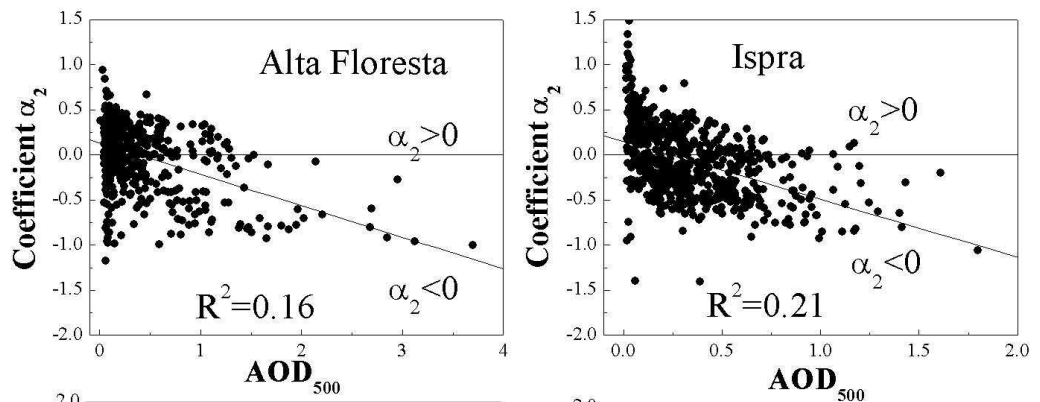

\section{Aerosol optical properties}

\section{G. Kaskaoutis et al.}
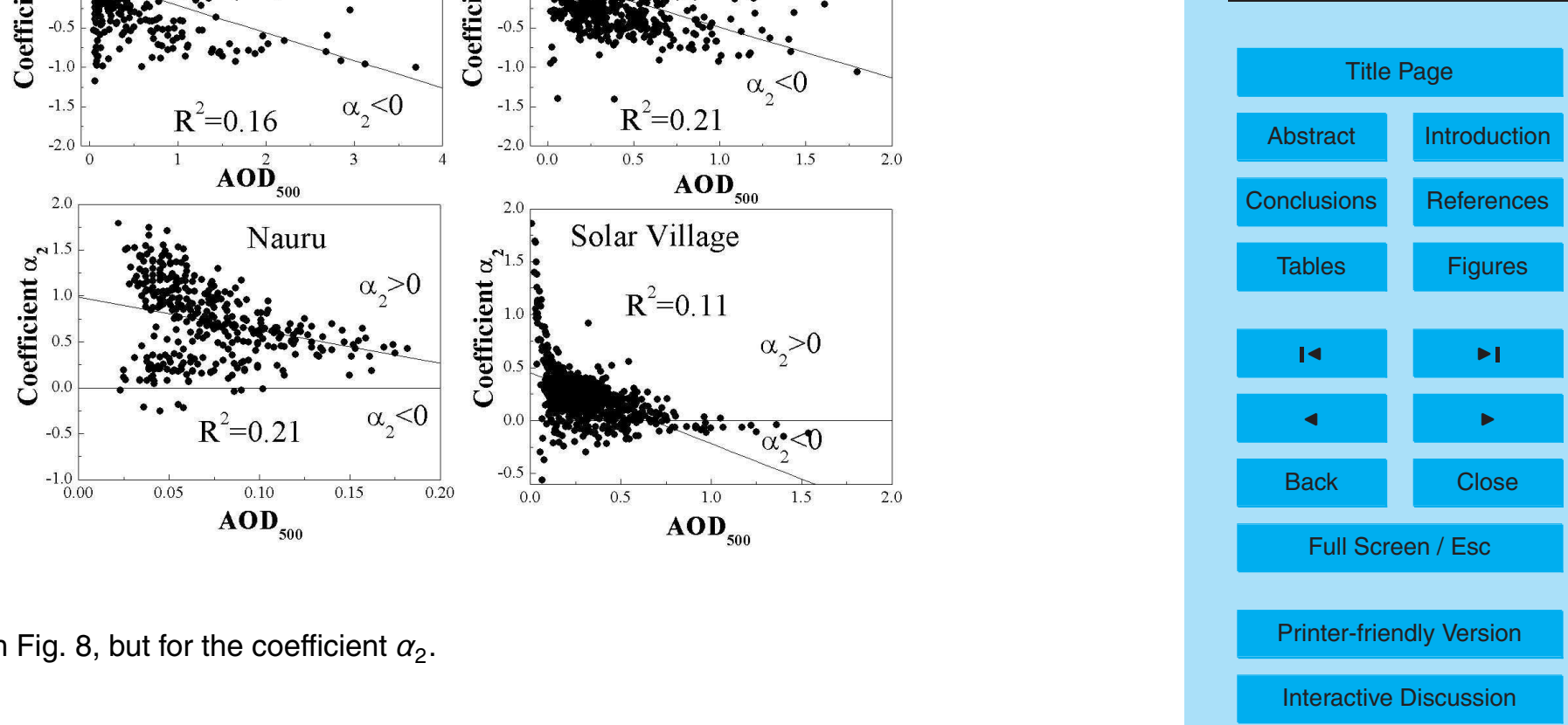

Fig. 9. As in Fig. 8, but for the coefficient $\alpha_{2}$. 


\section{ACPD}

\section{7, 7347-7397, 2007}

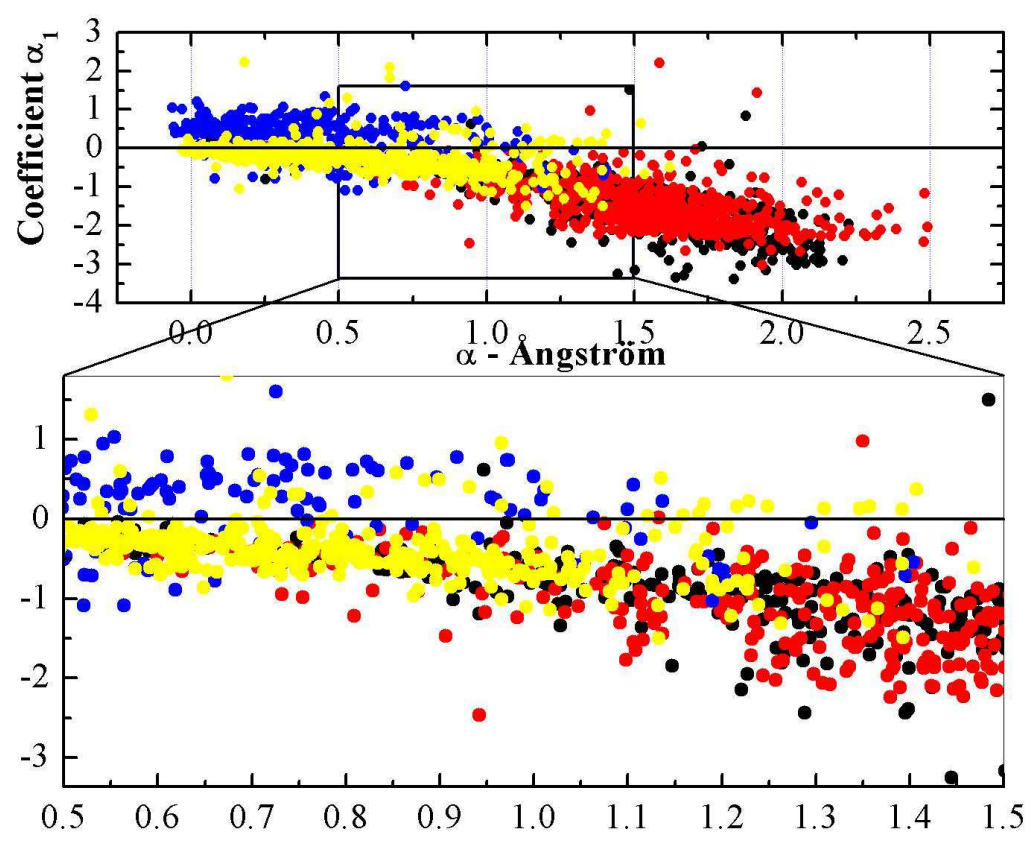

\section{Aerosol optical properties}

D. G. Kaskaoutis et al.

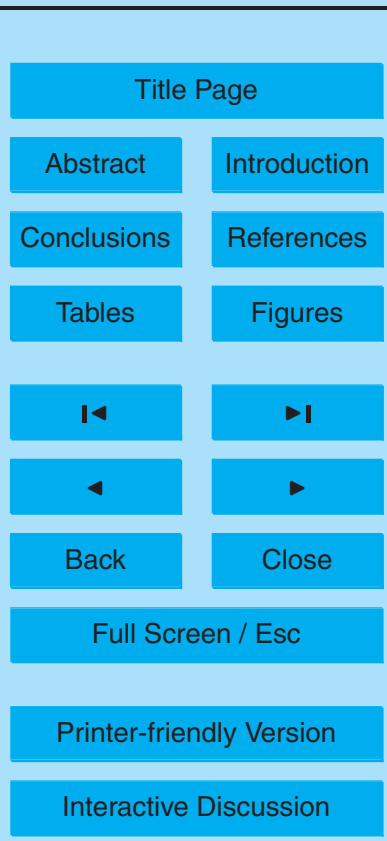




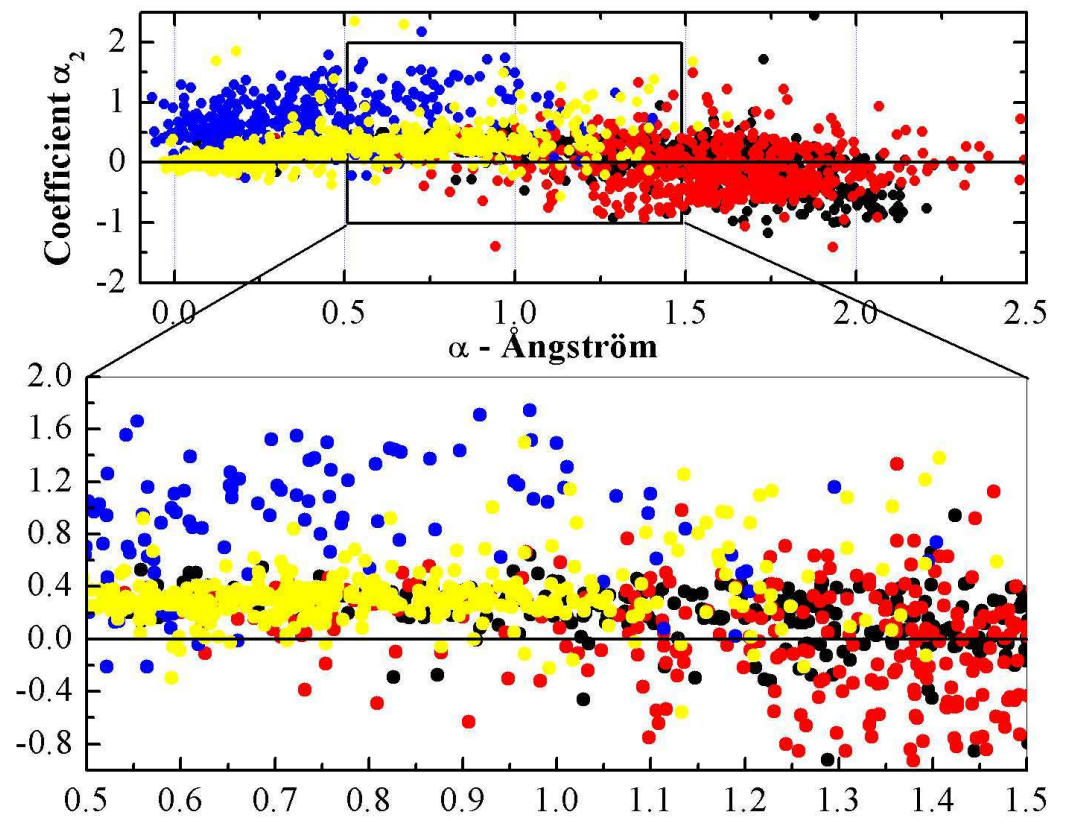

\section{7, 7347-7397, 2007}

\section{Aerosol optical} properties

\section{G. Kaskaoutis et al.}

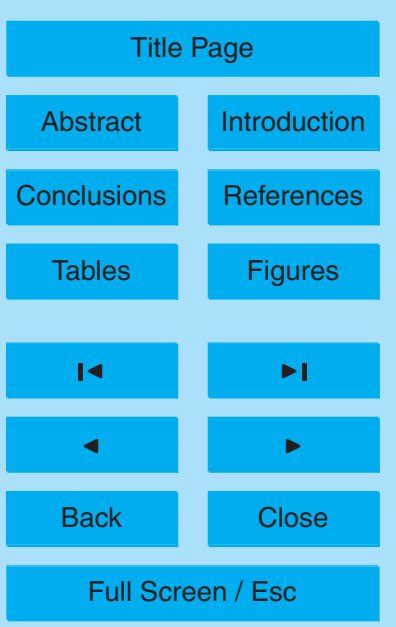

Fig. 11. As in Fig. 10, but for the coefficient $\alpha_{2}$. 


\section{ACPD}

7, 7347-7397, 2007

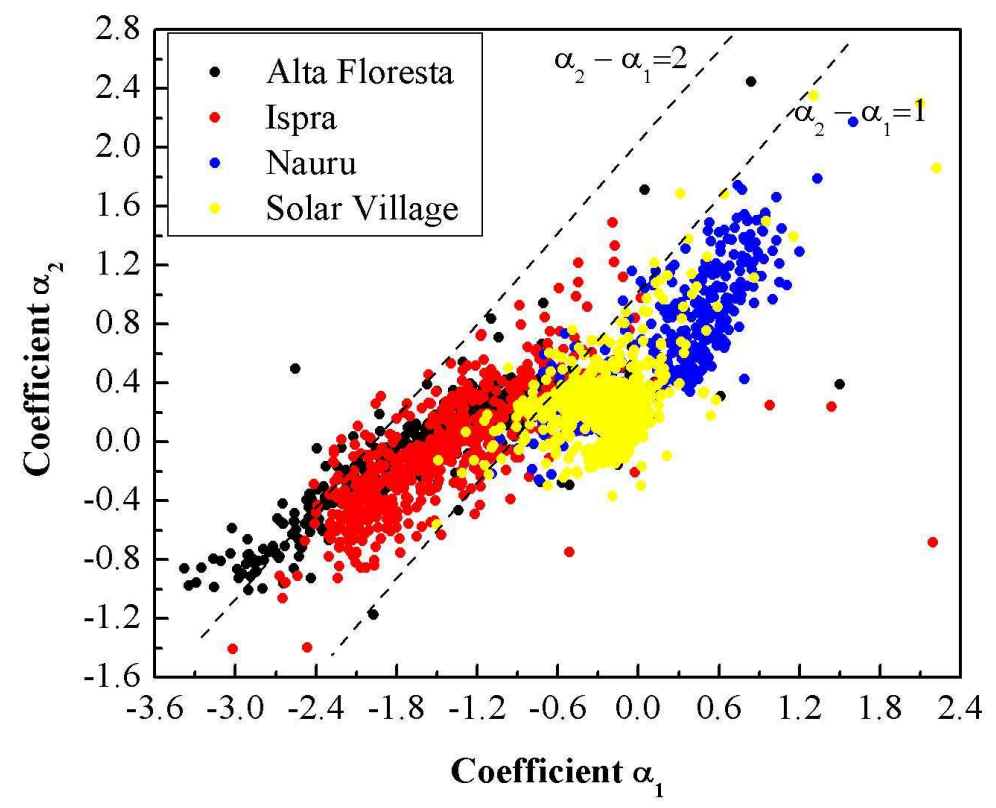

\section{Aerosol optical properties}

D. G. Kaskaoutis et al.

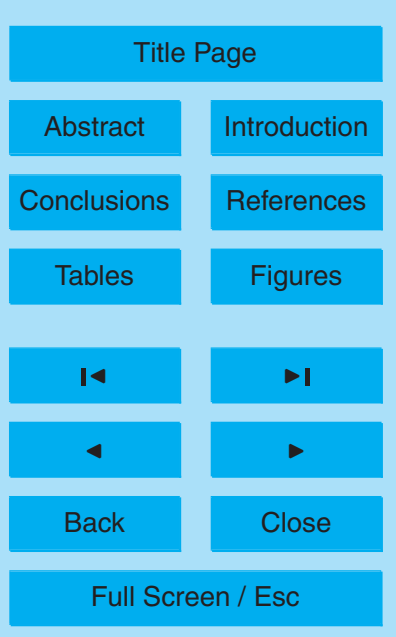

Fig. 12. Correlation between the coefficients $\alpha_{1}$ and $\alpha_{2}$ computed in the spectral interval 340-

Printer-friendly Version $870 \mathrm{~nm}$.

Interactive Discussion 


\section{ACPD}

\section{7, 7347-7397, 2007}

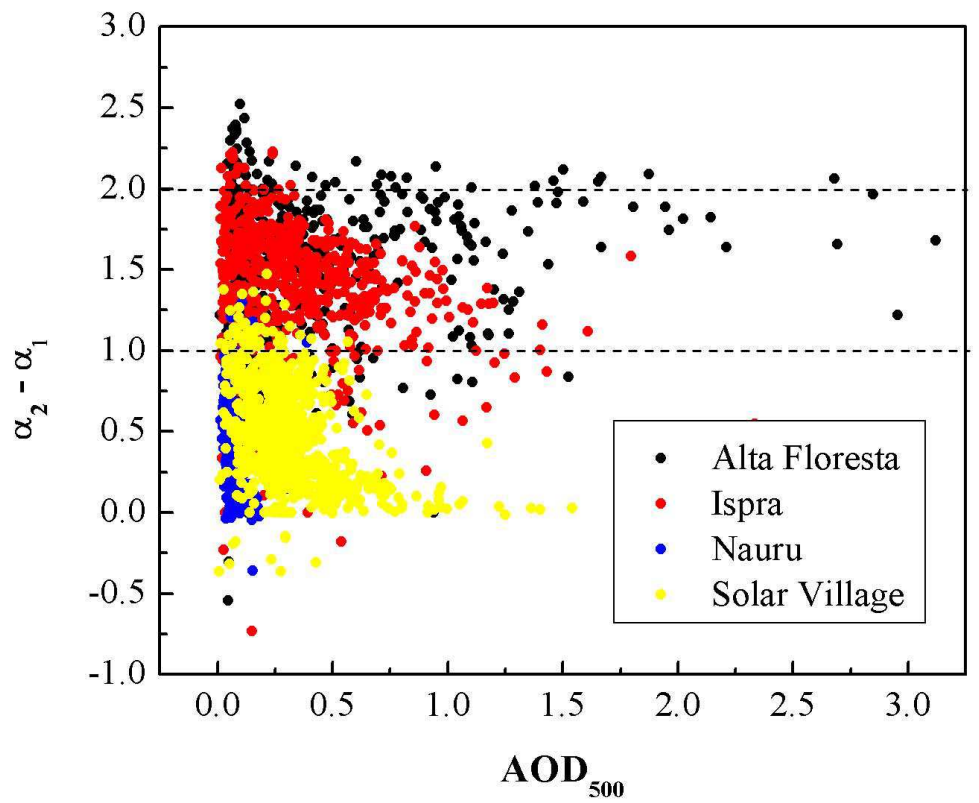

\section{Aerosol optical properties}

D. G. Kaskaoutis et al.

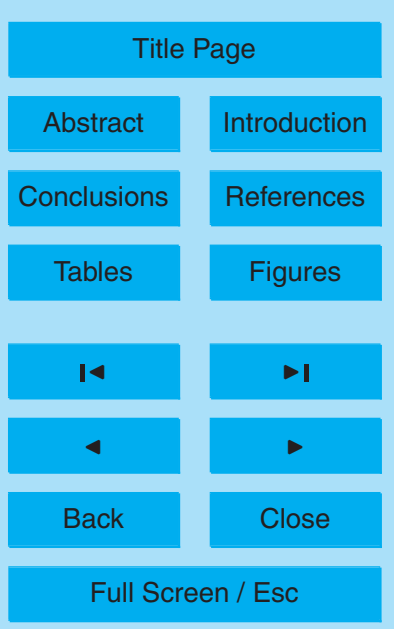

Fig. 13. Differences between the coefficients $\alpha_{2}$ and $\alpha_{1}$ as a function of $\mathrm{AOD}_{500}$ for the four representative AERONET sites. 


\section{ACPD}

\section{$7,7347-7397,2007$}
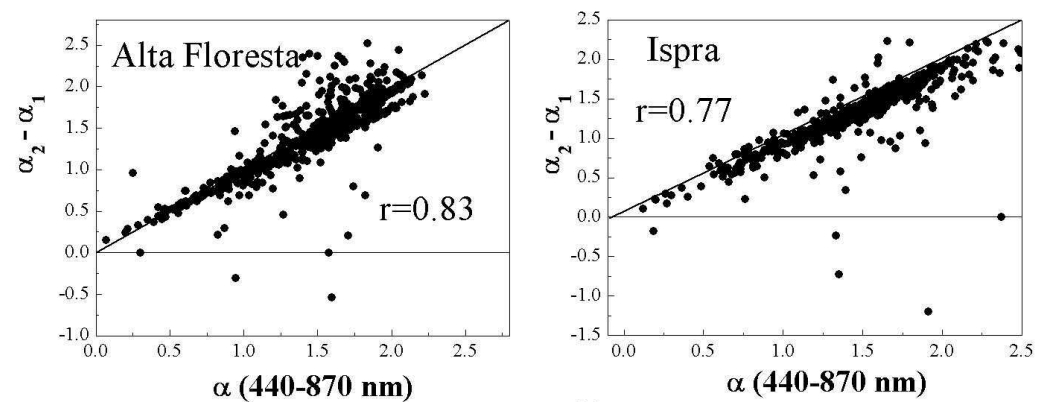

\section{Aerosol optical properties}

D. G. Kaskaoutis et al.
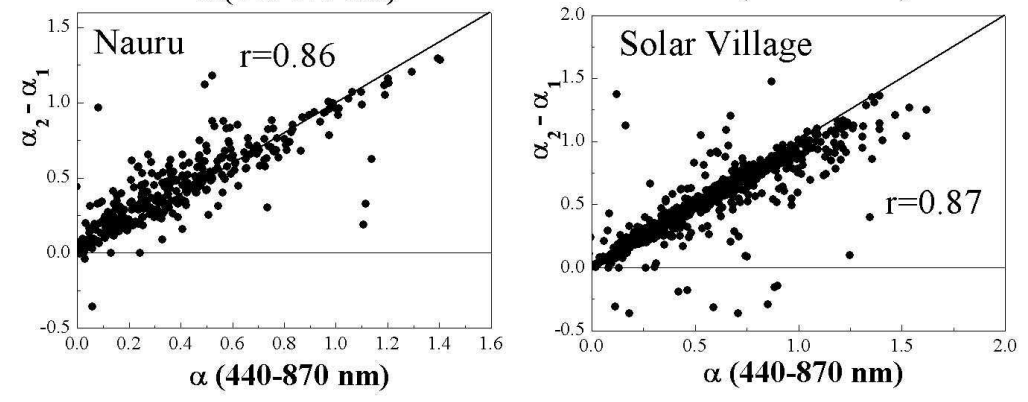

Title Page

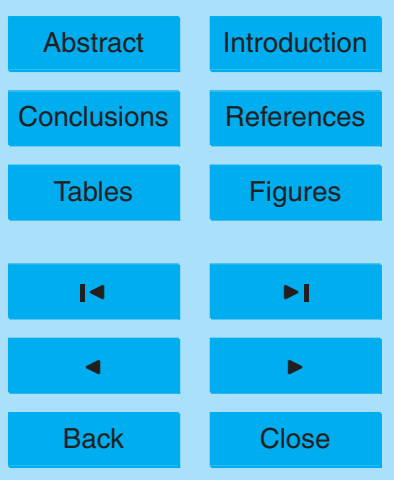

Full Screen / Esc

Fig. 14. Correlation between the differences $\alpha_{2}-\alpha_{1}$ and the AERONET Angstrom exponent values $\alpha_{440-870}$.

Printer-friendly Version

Interactive Discussion 


\section{ACPD}

\section{7, 7347-7397, 2007}
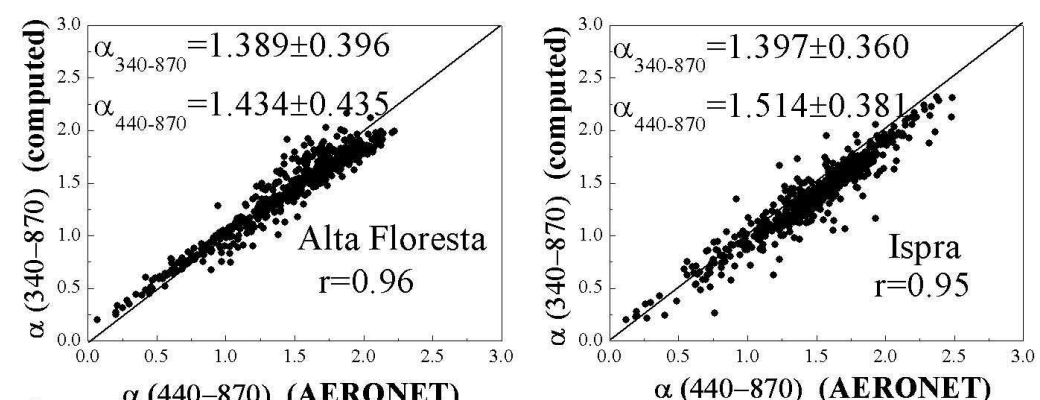

\section{Aerosol optical properties}

D. G. Kaskaoutis et al.
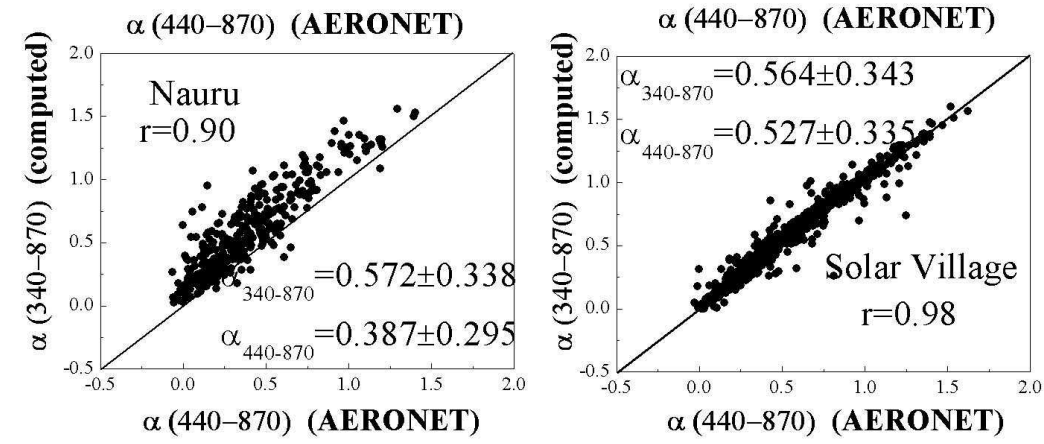

Fig. 15. Correlation between the computed values $\alpha_{340-870}$ and the values $\alpha_{440-870}$ obtained from AERONET for the four representative AERONET sites. 

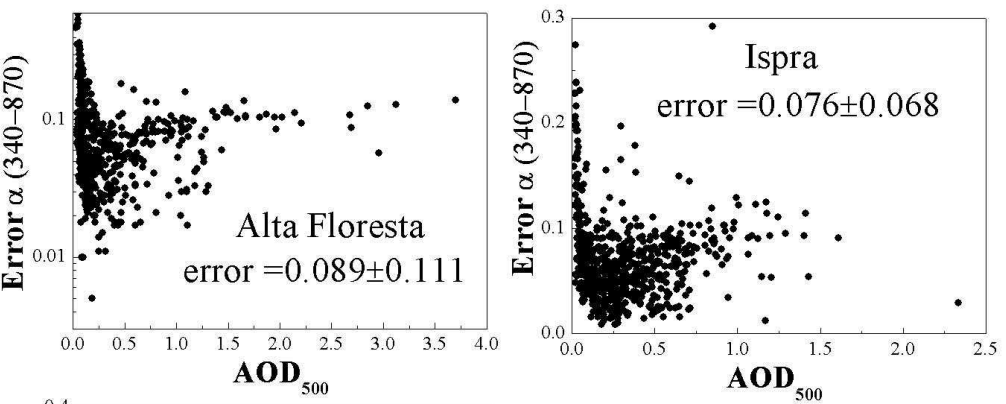

\section{ACPD}

$7,7347-7397,2007$

\section{Aerosol optical properties}

D. G. Kaskaoutis et al.
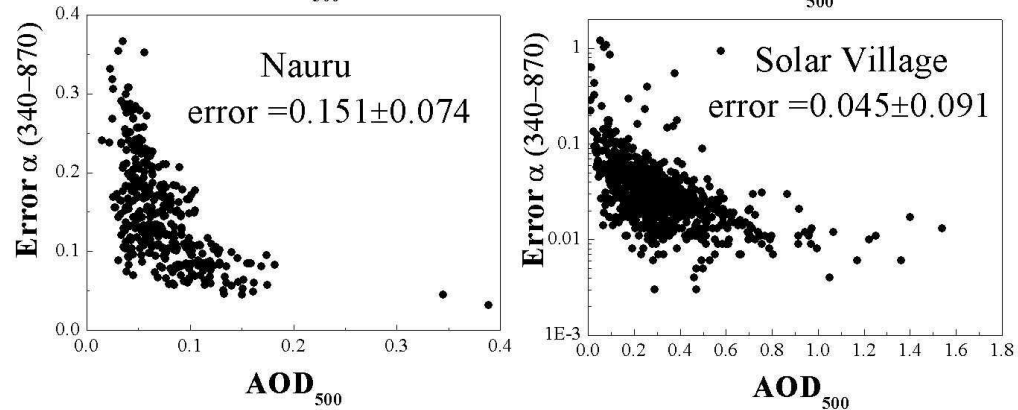

Title Page

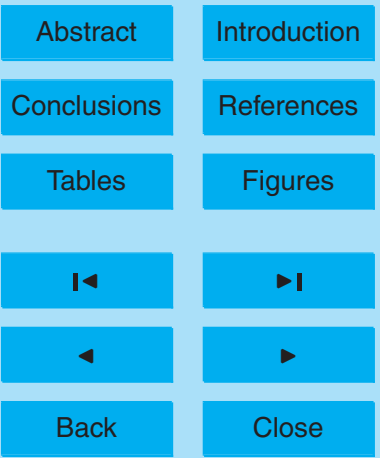

Full Screen / Esc

Fig. 16. Errors in computations of Angstrom exponent $\alpha_{340-870}$ using the least-squares method, as a function of $\mathrm{AOD}_{500}$.

Printer-friendly Version

Interactive Discussion 